\title{
Strategies to prevent anthracycline-induced cardiotoxicity in cancer survivors
}

\author{
Neha Bansal', M. Jacob Adams², Sarju Ganatra ${ }^{3,4}$, Steven D. Colan ${ }^{5}$, Sanjeev Aggarwal ${ }^{6}$, Rudolf Steiner ${ }^{7}$, \\ Shahnawaz Amdani ${ }^{8}$, Emma R. Lipshultz ${ }^{9,10}$ and Steven E. Lipshultz ${ }^{11,12,13^{*}}$
}

\begin{abstract}
Cancer diagnostics and therapies have improved steadily over the last few decades, markedly increasing life expectancy for patients at all ages. However, conventional and newer anti-neoplastic therapies can cause short- and long-term cardiotoxicity. The clinical implications of this cardiotoxicity become more important with the increasing use of cardiotoxic drugs. The implications are especially serious among patients predisposed to adverse cardiac effects, such as youth, the elderly, those with cardiovascular comorbidities, and those receiving additional chemotherapies or thoracic radiation. However, the optimal strategy for preventing and managing chemotherapyinduced cardiotoxicity remains unknown. The routine use of neurohormonal antagonists for cardioprotection is not currently justified, given the marginal benefits and associated adverse events, particularly with long-term use. The only United States Food and Drug Administration and European Medicines Agency approved treatment for preventing anthracycline-related cardiomyopathy is dexrazoxane. We advocate administering dexrazoxane during cancer treatment to limit the cardiotoxic effects of anthracycline chemotherapy.
\end{abstract}

Keywords: Cardiotoxicity, Cardio-oncology, Pediatrics, Beta-blockers, ACE inhibitors, Anthracyclines, Cancer

\section{Introduction}

The number of cancer survivors continues to increase as the success of cancer treatment regimens improves. The number of people in the US living after cancer is diagnosed to be 16.9 million as of Jan 2019 and are projected to increase to 21.7 million by 2029 [1]. In the early 1970 s, $12 \%$ of children who survived cancer of any type died within 15 years of diagnosis; by the early 1990s, the proportion had decreased to $6 \%[2,3]$.

Anthracyclines are still the chemotherapeutic drug class of choice for treating many cancers [4]. That fact remains the case, even with the introduction of a multitude of new cancer therapies over the past several years, such as targeted drugs and immunotherapies, with improvement in the overall morbidity and mortality of several different cancers [5-7]. Although many anti-neoplastic therapies are cardiotoxic, anthracycline-induced cardiomyopathy and heart failure (HF) are prototypical and the most

\footnotetext{
*Correspondence: slipshultz@upa.chob.edu; slipshultz@buffalo.edu

${ }^{11}$ Department of Pediatrics, University at Buffalo Jacobs School of Medicine

and Biomedical Sciences, Oishei Children's Hospital, 1001 Main Street, Buffalo, NY 14203, USA

${ }^{12}$ Oishei Children's Hospital, Buffalo, NY, USA

Full list of author information is available at the end of the article
}

thoroughly studied. In fact, the evidence increasingly shows that cancer and cardiovascular disease (CVD) are linked through common risk factors in both pediatric patients and in an aging population as well as through the adverse cardiovascular effects of cancer treatment.

Cardiovascular disease in general, and HF in particular, appear strongly related to cancer [8]. They share classical risk factors, including smoking, sedentary lifestyle, and obesity. Immunologic responses are critically important in cardiac remodeling and may have strong implications for the physiology of tumors. Immune checkpoint inhibitors have greatly improved clinical outcomes in several cancers, but they have also been implicated in several dozen reported cases of fulminant myocarditis, many of which resulted in death [9].

Early medical therapy for HF has greatly improved outcomes in the general population because such therapy can reverse, ameliorate, or prevent progressive left ventricular (LV) dysfunction [10]. Commonly used neurohormonal blocking drugs, such as angiotensin converting enzyme inhibitors (ACEI), angiotensin receptor blockers (ARB), beta-blockers $(\mathrm{BB})$, and aldosterone antagonists, reduce mortality or reverse LV remodeling in patients with non-

(c) The Author(s). 2019 Open Access This article is distributed under the terms of the Creative Commons Attribution 4.0 International License (http://creativecommons.org/licenses/by/4.0/), which permits unrestricted use, distribution, and 
cancer-related HF or with asymptomatic LV dysfunction. Their use has been explored in patients with chemotherapyinduced HF $[11,12]$. In fact, chemotherapy-induced cardiac dysfunction and symptomatic HF, in both children and adults, is now usually treated according to general cardiology guidelines for HF. However, evidence in support of using these drugs to treat, let alone prevent, HF caused by chemotherapy-induced cardiotoxicity is lacking. Furthermore, there is no clear consensus on the right time to administer these drugs. Most of the current cardio-oncology recommendations to prevent cardiotoxicity are largely based on opinion [13]. Increasingly, these medications are being investigated for preventing cardiotoxicity by administering them during cancer therapy. Physicians caring for survivors of cancer, especially childhood cancers, need to be aware of the benefits and the potential pitfalls of these medications if they are to make informed decisions for their patients [14].

Despite the cardiotoxicity associated with anti-neoplastic therapy, improperly discontinuing, interrupting, or reducing this therapy to avoid cardiotoxicity may lead to poorer overall outcomes. We found no studies reporting that reducing chemotherapy in patients with asymptomatic LV dysfunction leads to a better quality-of-life over a lifespan by providing oncologic efficacy on one hand and minimizing toxicities and late effects on the other $[15,16]$. However, identification of risk factors of cardiotoxicities in childhood cancer survivors via close surveillance is imperative to offer the preventive strategies currently available [17].

In this review, we summarize the primary and secondary strategies for preventing cardiotoxicity in cancer patients, especially that caused by anthracycline-containing cancer therapy.

\section{Characteristics of cardiotoxicity}

One of the most common manifestations of cardiotoxicity is LV dysfunction. However, the exact definitions of cardiotoxicity and a "significant" reduction in cardiac function are controversial [18]. The first controversy concerns the threshold of clinically important LV dysfunction. Current guidelines based on the criteria of the American Society of Echocardiography define cardiotoxicity as a $\geq 10 \%$ drop in left ventricular ejection fraction (LVEF) from baseline or an absolute value of $\leq 53 \%$ [19]. According to the European Society of Medical Oncology's Clinical Practice Guidelines Cardiac Review and Evaluation Committee [20], LV dysfunction is defined by "a) decrease in cardiac LVEF that is either global or more severe in the septum; b) symptoms of HF; c) signs of HF, including but not limited to the presence of a S3 gallop, tachycardia, or both; and d) a decline in LVEF of $\geq 5 \%$ to $\leq 55 \%$ with accompanying signs or symptoms of HF or a decline in LVEF of $\geq 10 \%$ to $\leq 55 \%$ without accompanying signs or symptoms." According to a 2016 European Society of Cardiology Position
Paper, echocardiography is the method of choice for detecting myocardial dysfunction before, during, and after cancer therapy. The paper defines cardiotoxicity as a decrease in LVEF of $>10 \%$ to a value $\leq 50 \%$, which is defined as the lower limit of normal [21].

The second controversy is how LV dysfunction is measured. The introduction of newer cardiac imaging technologies, such as cardiac magnetic resonance imaging (cMRI) and strain by echocardiography or cMRI, that can detect asymptomatic LV dysfunction, has led to the realization that the incidence of anthracycline-induced cardiotoxicity is substantially higher than previously thought when measured with echocardiography alone [22]. This unexpected incidence is even higher when assessed with serum cardiac biomarkers, which are validated surrogate endpoints for late echocardiographic evidence of cardiotoxicity in long-term survivors of childhood cancer treated with anthracyclines, but concentrations of these biomarkers may also be elevated despite clinically unimportant cardiac damage [23].

The third controversy is that none of these definitions or screening measures for LV dysfunction capture the damage anthracyclines and other anti-neoplastic drugs cause to the heart that manifest in ways other than LV systolic dysfunction, such as atherosclerotic disease, diastolic dysfunction, and intracardiac conduction abnormalities. Nevertheless, at present, the most frequently used modalities for detecting cardiotoxicity are the periodic measurement of LVEF by echocardiography or cMRI, with echocardiography being the predominant technology for screening cancer patients [20]. The American Society of Clinical Oncology guidelines recommend continuous surveillance of all adults with a history of cancer treatment by means of a thorough history and physical and serial echocardiograms or cMRIs (in the case of poor echocardiographic images) in patients considered at high-risk for cardiotoxicity [24]. Newer imaging technologies, such as echocardiographic myocardial strain and strain rate, can also detect toxicity before abnormalities in the LVEF become apparent [16]. The American Society of Echocardiography and the European Association of Cardiovascular Imaging Guidelines recommend assessing global longitudinal strain as a routine component of clinical echocardiographic exams in adults at risk for cardiotoxicity [25]. No such guidelines exist for children. However, these modalities depend on LV loading conditions and heart rate, which are often disturbed in cancer patients [16]. Indicators of LV function provided by imaging modalities, including LVEF, decline during therapy and are poor predictors of chronic cardiomyopathy after therapy [16]. Thus, relying on monitoring modalities to modify lifesaving chemotherapy doses may do more harm than good in cancer patients without clinical cardiovascular symptoms of HF. 
A large unknown is the effect of cardiac monitoring and consequent dose reductions on cancer cure rates [15]. In spite of published guidelines, whether therapeutic decisions based on asymptomatic changes in LV function will improve overall survival or quality-of-life for these patients is unknown. Therefore, we do not support altering oncologic therapy based on echocardiographic changes in cancer patients without symptomatic cardiac disease.

Practice guidelines may affect clinical practice. Although they are imperfect and are a work-in-progress, they remain the cornerstone for informing clinical decisions [26]. However, to provide the most accurate state of the existing data on which practice guideline are developed the authors must delineate the quality of available data that support these guidelines. Further efforts evaluating longitudinal data and testing practice guidelines prospectively remain critical given the possibility that they might be causing harm.

\section{Principles for preventing cardiotoxicity}

The relationship between cancer and CVD is bidirectional [27]. Well known risk factors for CVD, such as tobacco use, obesity, physical inactivity, poor nutrition, diabetes, excessive alcohol consumption, hypertension, and hyperlipidemia, are also risk factors for cancer [8]. An individual's cardiovascular risk factors, such as hypertension, in a cancer survivor appeared to carry greater risk than the same risk factors in an individual without a history of cancer [28]. Additionally, each additional risk factor in a cancer survivor appears to impart a more-than-additive increase in the risk of CVD $[29,30]$. Further, cancer survivors are more likely to have traditional cardiovascular risk factors than are their age-matched healthy controls [31]. Cancer patients with pre-existing CVD or cardiovascular risk factors are at higher risk for cardiac complications [32]. As a result, the traditional CVD risk factors cited above must be aggressively managed in this high-risk population, regardless of the type of cancer or treatment, to minimize the risk of adverse outcomes [32]. Further, cholesterol metabolites activate estrogen receptors and stimulate breast tumor growth [33]. Thus, lowering cholesterol levels through lifestyle modifications, medication, or exercise-all proven cardioprotective interventions-may also reduce the risk of breast cancer or at least slow the rate of tumor growth [34, 35].

Recent epidemiological studies, like a large Danish cohort, have reported a higher incidence of cancer in patients with HF (mean incidence rate ratio, 1.24; 95\% CI, 1.15 to $1.33 ; P<0.001$ ), and their prognosis was worse [36]. Thus, some authors have proposed that HF might represent an oncogenic condition [27].

\section{Anthracycline-induced cardiotoxicity}

Anthracyclines are used extensively to treat lymphoma, sarcoma, breast cancer, and many pediatric cancers [22, 31]. About a third of women with breast cancer and half the children with cancer are treated with anthracyclines [37]. Unfortunately, anthracyclines can irreversibly damage the myocardium. The Childhood Cancer Survivor Study reported that among patients who survived at least 5 years, the cumulative incidence of cardiac disease 30 years from diagnosis was $4.8 \%$ (95\% CI, 4.3 to 5.2 ) in 24,214 patients with a median attained age of 27.5 (range, 5.6 to 58.9 ) years [38]. There was a dose-response relationship between anthracycline chemotherapy and HF, with children up to age 13 years being at the greatest risk for HF after dosing similar to that of older children [38].

Anthracycline-related cardiotoxicity ranges from subclinical cardiomyopathy to HF to cardiac death. HF may occur within the first week of anthracycline treatment or even decades later [39]; however, most cases occur within the first year after treatment [19]. In fact, for at least the past two decades, anthracycline-induced HF has been a leading co-morbidity in survivors of childhood cancers [40]. In 1022 children with acute myeloid leukemia treated in the Children's Oncology Group trial, $12 \%$ experienced cardiotoxicity (grade 2 or higher LV systolic dysfunction) during 5 years of follow-up, with more than $70 \%$ of incident events occurring during onprotocol therapy [41]. Both event-free survival (hazard ratio [HR], 1.6, $95 \% \mathrm{CI}, 1.2$ to $2.1 ; P=0.004)$ and overall survival (HR, 1.6; 95\% CI, 1.2 to $2.2 ; P=0.005$ ) were significantly worse in patients with documented cardiotoxicity (defined in this study as resting $\mathrm{SF}<24 \%$ or $\mathrm{EF}<50 \%$ ).

The evidence of increased risk of CVD in cancer survivors is overwhelming. The risk is largely attributable to toxic cancer treatments, augmented by traditional cardiovascular risk factors developing later in life [32]. In a Scientific Statement from the American Heart Association (AHA) on CVD and breast cancer, the authors note that for older women, CVD poses a greater mortality threat than breast cancer itself [42]. Another AHA Scientific Statement summarizes a large amount of evidence on cardiotoxicity in children, adolescents, and young adults treated for cancer [43]. Not surprisingly, interest in preventing, minimizing, or delaying these cardiotoxic side effects remains high and continues to foster research, as well as debate.

\section{Primary prevention of anthracycline-induced cardiotoxicity}

Strategies to prevent anthracycline-induced HF can be classified as primary or secondary [22]. Preventing cardiac damage at the time of cancer therapy (primary prevention) would be ideal, and in fact, evidence-based strategies can reduce the risk of such damage. Secondary 
prevention is used to refer to preventing progression to symptomatic disease, such as HF, after asymptomatic LV dysfunction has been found. The American Society of Clinical Oncology guidelines [24], endorsed by the AHA, recommend that oncologists supported by cardiologists consider several primary prevention strategies during cancer treatment.

Prevention of cardiotoxicity should be addressed by medical care providers before cancer treatment, especially with anthracyclines [44]. In addition to the specific treatment-related risks in survivors of childhood cancer, CVD risk factors are more common in these patients and present important opportunities for intervention and thus primary prevention [45]. As highlighted by the AHA Scientific Statement, Cardiovascular Risk Reduction in High-Risk Pediatric Patients, cardiovascular risk should be reduced with interventions such as counseling on maintaining appropriate weight, eating a hearthealthy diet, getting adequate exercise, and avoiding tobacco exposure [45].

\section{Dexrazoxane cardioprotection}

Dexrazoxane is the only FDA- approved drug for preventing anthracycline-induced cardiotoxicity [46]. In August 2014, the FDA designated dexrazoxane as an orphan drug for "prevention of cardiomyopathy for children and adolescents 0 through 16 years of age treated with anthracyclines" [47]. However, citing reports that dexrazoxane might cause secondary malignant neoplasms and reduce the efficacy of doxorubicin, the European Medicines Agency (EMA) approved dexrazoxane only for women receiving doxorubicin for advanced breast cancer who require a cumulative doxorubicin dose $>300 \mathrm{mg} / \mathrm{m}^{2}$ [48]. Then, in 2017, after a careful review of dexrazoxane's risk-benefit profile, in a rare move, the EMA overturned its earlier decision and now allows dexrazoxane to be given to children and adolescents who are likely to be treated with high cumulative doses of anthracyclines (>300 mg/m ${ }^{2}$ of doxorubicin) [49, 50]. This recent decision allows virtually all children to receive dexrazoxane starting with the first dose of anthracycline at the discretion of the treating provider [51]. The label change announcing dexrazoxane as an approved cardiac protectant was followed with a review of the evidence by the EMA, which is posted and updated on its website [50,51].

In a study of Wistar rats, a single dose of doxorubicin $(20 \mathrm{mg} / \mathrm{kg})$ increased circulating cardiac troponin I concentrations and decreased cardiac mass by $7.6 \%$ [52]. A 7-week regimen of doxorubicin clearly impaired the mitochondria. In a randomized, controlled trial (RCT), serum concentrations of cardiac troponin $\mathrm{T}$ (cTnT) (a validated biomarker of active cardiomyocyte injury) measured several times before, during, and after doxorubicin infusion in patients treated with or without dexrazoxane, found that concentrations were elevated in $20 \%$ of children who received dexrazoxane before every dose of doxorubicin but in $47 \%$ of those who did not [53]. Thus, dexrazoxane should not be withheld from any child being treated with anthracyclines, irrespective of the cumulative dose [54].

Dexrazoxane binds iron before it enters cardiomyocytes $[55,56]$, which prevents the formation of the ironanthracycline complex, thereby preventing free radical formation and thus, cardiac damage (Fig. 1). In addition, dexrazoxane can change the configuration of topoisomerase $2 \beta$, preventing anthracyclines from binding to it [22], further preventing cardiomyocyte death, mitochondrial dysfunction, and the supression of anti-oxidant gene expression [57].

Throughout its development in animal models and human studies [51, 58], dexrazoxane has consistently proven to be cardioprotective. Its acute and long-term efficacy has been confirmed in clinical studies in adults and children since the mid-1990s [59]. It has been successfully used as a cardioprotectant against anthracycline-induced cardiotoxicity in a variety of solid and hematological malignancies in adults and children receiving doxorubicin and other anthracycline drugs [49]. Multiple studies have reported that children, adolescents, and adults treated with doxorubicin and dexrazoxane have less subclinical cardiotoxicity (asymptomatic LV dysfunction) [53, 59], better LV performance [53, 60-62], and fewer cardiac events than patients not receiving dexrazoxane [63]. A Cochrane meta-analysis of 10 randomized trials on dexrazoxane (1619 pooled adults) found that dexrazoxane markedly reduced the occurrence of HF (relative risk (RR), $0.29 ; 95 \%$ CI, 0.20 to 0.41) [64]. Recently, five consecutive patients with preexisting, asymptomatic, LV systolic dysfunction who received anthracycline-based chemotherapy were concomitantly treated off-label with dexrazoxane, administered $30 \mathrm{~min}$ before each anthracycline dose, regardless of cancer type or stage [65]. In these patients, changes in LV systolic function were minimal, with a mean LVEF decreasing from $39 \%$ at baseline to $34 \%$ after chemotherapy. No patient experienced symptomatic HF or elevated cardiac troponin I or brain natriuretic peptide concentrations [65]. Meta analyses of randomized trials have suggested that dexrazoxane decreases the risk of both clinical and asymptomatic HF during and shortly after therapy [66].

As mentioned above, the authors of a prospective study of Hodgkin's disease claimed that dexrazoxane might have increased the incidence of myelodysplastic syndrome and secondary cancers [67]. However, later and larger studies of those patients or of other patients with various cancers found no increase in the incidence of secondary malignancies in patients receiving dexrazoxane $[68,69]$, and dexrazoxane did 


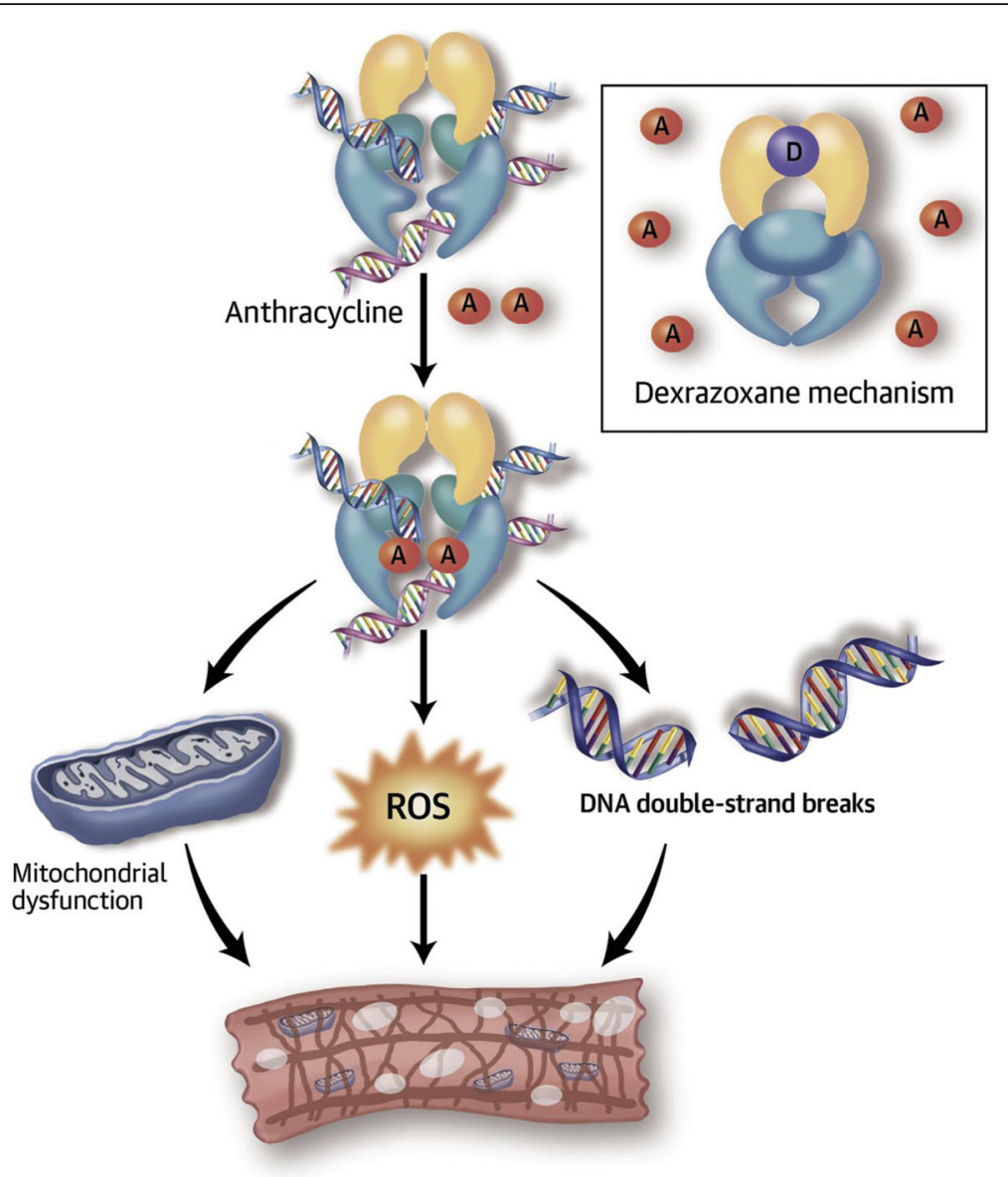

Fig. 1 Doxorubicin (an anthracycline, A) disrupts the normal catalytic cycle of topoisomerase $2 \beta$, causing deoxyribonucleic acid (DNA) doublestranded breaks. Doxorubicin also changes the transcriptome, leading to defective mitochondrial biogenesis and increasing reactive oxygen species (ROS). As a result, cardiomyocytes show myofibrillar disarray and vacuolization. In the inset, dexrazoxane binds to topoisomerase $2 \beta$ to prevent anthracycline binding. Produced by permission from Vejpongsa P, Yeh ETH. J Am Coll Cardiol 2014;64:938-45

not compromise long-term survival [70]. In a more recent study of 1453 patients, secondary malignancies were not related to dexrazoxane administration [71].

In a long-term study of 94 survivors of childhood cancer treated with doxorubicin (mean dose, $279 \mathrm{mg} / \mathrm{m}^{2}$ ), with or without dexrazoxane, those receiving only doxorubicin had a non-significant reduction in LV fractional shortening (FS; mean [SD], 33.0\% [4.8\%] versus $34.8 \%$ [4.6\%], respectively; $P=0.10$ ) but greater myocardial wall stress and dysfunction as measured by mean (SD) B-type natriuretic peptide (BNP) concentrations (18.3 [14.7] pg/ $\mathrm{mL}$ versus $11.3[10.6] \mathrm{pg} / \mathrm{mL} ; P=0.02$ ) and $N$-terminal B-type natriuretic peptide (NT-proBNP) concentrations (64.8 [55.5] versus 44.5 [39.0] $\mathrm{pg} / \mathrm{mL} ; P=0.06$ ) [72].

In summary, the evidence for dexrazoxane's effectiveness in reducing anthracycline-related cardiotoxicity in adults and children-without reducing antitumor efficacy and without increasing the incidence of second malignancies-is overwhelming. Research has revealed that predictive biomarkers of early anthracycline cardiotoxicity may be useful for optimizing treatment strategies through earlier implementation of cardioprotective interventions or by preventing anthracycline-associated cardiotoxicity [73]. Currently, the routine use of blood and imaging biomarkers in asymptomatic cancer patients remains limited, primarily because of a lack of evidence of utility [46].

Despite the compelling evidence of dexrazoxane's cardioprotective efficacy, it is not routinely administered to many children, adolescents, or adults. However, the DanaFarber Cancer Institute's Childhood Acute Lymphoblastic Leukemia Consortium and the Children's Oncology Group currently include dexrazoxane in their research protocols that involve anthracyclines [74]. Although dexrazoxane markedly suppresses anthracycline cardiotoxicity, its cardioprotective activity is not complete because anthracyclines have several potential cardiotoxic mechanisms, and dexrazoxane interferes with some, but not all, of these mechanisms $[58,75,76]$. In fact, there is no safe dose of anthracyclines [29]. Thus, the search for the perfect combination of primary cardioprotectants continues. 
Neurohormonal blocking drugs: Beta-blockers, angiotensin converting enzyme inhibitors, angiotensin receptor blockers, and aldosterone antagonists Preclinical studies

Beta-blockers are used extensively to treat HF because of their ability to block the neurohormonal cascade that progresses to heart disease. The additional antioxidant activity of carvedilol and nebivolol has been used to justify their use for primary prevention of anthracycline cardiotoxicity. The effect of BBs for preventing specific cardiotoxic effects appears to depend on which specific receptor is being blocked. In one preclinical study in mice, the beta- 1 adrenergic receptors mediated some of the acute anthracycline cardiotoxicity [77]. However, in that study, the cardioprotective rescue effect of a beta-1 receptor deletion in anthracycline-treated mice was not reproduced using the beta-1 receptor selective antagonist, metoprolol [77].

Another study evaluating metoprolol given 1 week after beginning doxorubicin therapy found no survival advantage in rats, although LV function improved [78]. On the other hand, metoprolol given to rats 3 weeks after exposure to doxorubicin temporarily down-regulated betaadrenergic receptor density and increased attenuation of plasma norepinephrine concentrations [79]. The metoprolol-treated rats also had normal LV end-diastolic pressures. These findings suggest that metoprolol did temporarily reduce acute doxorubicin cardiotoxicity. However, the study did not address long-term cardioprotection [79]. In a third rat study, metoprolol prevented the increase in $\mathrm{Ca}^{2+}$-ATPase, a mechanism for doxorubicininduced cardiotoxicity, suggesting that it has cardioprotective potential [80]. However, in contrast to the study described above [79], the density of beta-adrenergic receptors was not reduced. A 2015 study of 30 mice found that LVEF was significantly lower in those receiving doxorubicin without carvedilol than in those receiving doxorubicin with carvedilol [81].

In survivors of childhood acute lymphoblastic leukemia, doxorubicin-treated patients had an abnormally greater number of mitochondrial DNA copies per cell than did those who also received dexrazoxane [82]. This finding suggests that a higher number of mitochondrial DNA copies is required to maintain normal mitochondrial function in patients with cardiotoxicity and implicates mitochondrial damage as part of the cardiotoxicity mechanism [82]. However, in a study of rat cardiomyocytes, metoprolol did not protect against doxorubicin-induced alterations in mitochondrial DNA in regions regulating oxidative phosphorylation [83]. These contrasting results in animal studies call into question the validity of the animal models and the likelihood that metoprolol would be effective primary prevention [58].

Both ACEIs and ARBs help lower blood pressure by angiotensin blockade and thus reduce afterload, which helps cardiac function. However, two animal studies have investigated the potential of ACEIs to prevent anthracycline-induced cardiotoxicity. One randomized study in rats reported that zofenopril was more effective than enalapril or valsartan in preventing increases in doxorubicin-induced cardiomyopathy, as assessed by serum cardiac troponin I (cTnI) concentrations and histopathologic analyses [84]. This study is difficult to interpret because it did not use a true control population; rather, researchers used an ex-vivo model of stopping perfusion to an isolated rat heart after euthanasia. Thus, it is not clear whether the study evaluated a preventive effect against anthracycline damage alone, as opposed to a combined ischemic and anthracycline mechanism [84]. In another study of rats treated with doxorubicin, enalapril significantly attenuated the decrease in LVFS seen in control rats treated with only doxorubicin [85].

\section{Clinical studies in adults}

Beta-blockers Early clinical studies have had mixed results in using BBs at the time of chemotherapy to prevent anthracycline-associated HF in adults (Table 1).

The Carvedilol Effect in Preventing ChemotherapyInduced Cardiotoxicity (CECCY trial) was an RCT of carvedilol versus placebo in 192 women with HER2negative breast cancer. The primary endpoint of $\mathrm{a} \geq 10 \%$ decrease in LVEF within 6 months of starting chemotherapy occurred in 14 patients (14.5\%) in the carvedilol group and in 13 patients (13.5\%) in the placebo group $(P=0.99)$ [86]. Changes in LVEF and BNP concentrations did not differ between groups. However, the carvedilol group had lower mean serum cTnI concentrations over 24 weeks $(P=0.003)$ and a lower incidence of LV diastolic dysfunction $(P=0.04)$. The authors concluded that carvedilol did not affect the incidence of early reductions in LVEF [86].

In a placebo-controlled clinical trial of prophylactic carvedilol used from the start of chemotherapy, after 6 months of follow-up, mean LVEF was similar to baseline in the carvedilol group ( $n=25 ; 70.5$ versus 69.7 , respectively; $P=0.3$ ) but was significantly lower in the control group $(\mathrm{n}=25 ; 68.9$ versus 52.3; $P<0.001)$ [87]. Doppler echocardiography showed that although the E-wave velocities in the carvedilol group were reduced, both the Ewave velocities and the E/A ratios were also significantly reduced in the control group [87]. Of the 5 patients who died, 4 were in the control group and 1 was in the carvedilol group; the difference was not significant. Unfortunately, cause of death was not discussed in the article.

In a third study, women with breast cancer treated with doxorubicin were randomly assigned to receive either a low daily dose of carvedilol $(n=30)$ or placebo 
Table 1 Summary of studies for primary prevention of anthracycline-induced cardiotoxicity with beta-blockers, angiotensinconverting enzyme inhibitors, angiotensin receptor blockers, and aldosterone antagonists

\begin{tabular}{|c|c|c|c|c|c|}
\hline Reference & Medications & $\begin{array}{l}\text { Patients } \\
\text { (groups), } N^{a}\end{array}$ & $\begin{array}{l}\text { Follow-Up, } \\
\text { mean (SD) Months }\end{array}$ & $\begin{array}{l}\text { Imaging } \\
\text { Modality }\end{array}$ & Results by group \\
\hline Avila et al. [86] & $\begin{array}{l}\text { Carvedilol ( } 3.125 \text { mg BID } \\
\text { increasing every } 3 \text { weeks to } \\
\text { max } 25 \text { mg BID) vs. placebo }\end{array}$ & $192(96 / 96)$ & 6 & Echo & $\begin{array}{l}\text { Carvedilol LVEF } 65.2 \% \rightarrow 63.9 \% \\
\text { Placebo LVEF } 64.8 \% \rightarrow 63.9 \% \\
P=0.84 \\
\text {-Lower troponin I levels in the carvedilol group } \\
(P=0.003) \\
\text {-Lower incidence of diastolic dysfunction in the } \\
\text { carvedilol group }(P=0.04)\end{array}$ \\
\hline Kalay et al. [87] & $\begin{array}{l}\text { Carvedilol }(12.5 \mathrm{mg}) \text { daily vs. } \\
\text { placebo }\end{array}$ & $50(25 / 25)$ & $5.2(1.2)$ & Echo & $\begin{array}{l}\text { Carvedilol: LVEF } 70.5 \% \rightarrow 69.7 \% \\
\text { Placebo: LVEF } 68.9 \% \rightarrow 52.3 \%+ \\
\text { RR: } 0.2(0.03-1.59)\end{array}$ \\
\hline $\begin{array}{l}\text { Tashakori et al. } \\
{[88]}\end{array}$ & Carvedilol $^{b}$ vs. control & $70(30 / 40)$ & 1 week & $\begin{array}{l}\text { Strain by } \\
\text { Speckle } \\
\text { Tracking } \\
\text { Echo }\end{array}$ & $\begin{array}{l}\text { No significant reduction in strain and strain-rate } \\
\text { parameters after intervention, compared to control } \\
\text { group }(P<0.001)\end{array}$ \\
\hline Elitok et al. [89] & Carvedilol $^{\complement}$ vs. control & $80(40 / 40)$ & 6 & Echo & $\begin{array}{l}\text { - Mean LVEF, LVFS, and LV dimensions similar } \\
\text { before and after cancer therapy } \\
\text { - Significantly worse LV basal septal (0.7 vs. 0.94) } \\
\text { and lateral peak systolic strain (0.72 vs. 1.08) in } \\
\text { control group after treatment while these } \\
\text { measures did not differ between treatment } \\
\text { groups at baseline. } \\
\text { - No clinical cardiotoxic events in either group }\end{array}$ \\
\hline Nabati et al. [96] & Carvedilol & $91(45 / 46)$ & 6 & Echo & $\begin{array}{l}\text { - Carvedilol: No change in mean LVEF } \\
\text { - Control: Mean drop of } 10 \% \text { LVEF } \\
\text { Placebo group had a higher frequency of Tnl } \\
\text { concentrations }>0.05 \text { at } 30 \text { days ( } 48.6 \% \text { vs. } 24.4 \% \text {, } \\
P=0.03 \text { ) }\end{array}$ \\
\hline $\begin{array}{l}\text { Jhorawat et al. } \\
\text { [90] }\end{array}$ & Carvedilol $^{c}$ vs. control & $54(27 / 27)$ & 6 & Echo & $\begin{array}{l}\text { Carvedilol: LVEF } 63.19 \% \rightarrow 63.88 \% \\
\text { LVFS } 34 \% \rightarrow 34.6 \% \\
\text { Control: LVEF } 67.27 \% \rightarrow 60.82 \%+ \\
\text { LVFS } 38.48 \% \rightarrow 34.6 \dagger \\
\text { LV end-systolic diameter } \\
\text { Control mean (SD): } 28.26(5.50 \mathrm{~mm} \rightarrow 31.25 \text { (6.50) } \\
\text { mmt) } \\
\text { Carvedilol: unchanged }\end{array}$ \\
\hline Kaya et al. [91] & $\begin{array}{l}\text { Nebivolol (5 mg) daily vs. } \\
\text { placebo } f\end{array}$ & $45(27 / 18)$ & 6 & Echo & $\begin{array}{l}\text { Nebivolol: LVEF } 65.6 \% \rightarrow 63.8 \% \\
\text { Placebo: LVEF } 66.6 \% \rightarrow 57.5 \% \dagger \\
(P=0.01)\end{array}$ \\
\hline $\begin{array}{l}\text { Cardinale et al. } \\
\text { [93] }\end{array}$ & $\begin{array}{l}\text { Enalapril at start of } \\
\text { chemotherapy (prevention } \\
\text { arm) vs. troponin triggered } \\
\text { enalapril therapy }\end{array}$ & $\begin{array}{l}273(136 / \\
137)\end{array}$ & 12 & Echo & $\begin{array}{l}\text { Troponin elevation incidence: Prevention group: } \\
23 \% \text { vs. Troponin triggered group } 26 \% \text { ( } P=0.50) \\
\text { Cardiotoxicity incidence: } 2 \text { in prevention group vs. } \\
1 \text { in troponin-triggered group }\end{array}$ \\
\hline $\begin{array}{l}\text { Janbabai et al. } \\
\text { [94] }\end{array}$ & $\begin{array}{l}\text { Enalapril (17.94 [4.10] mg) vs. } \\
\text { control }\end{array}$ & $69(34 / 35)$ & 6 & Echo & $\begin{array}{l}\Delta \text { mean LVEF from baseline at } 6 \text { months: } 0.55 \text { vs. } \\
-13.3, P<0.001 \\
\text { In the enalapril group, tissue Doppler, E/e' ratio, mean } \\
\text { LVEF and cTnl and CK-MB levels were significantly } \\
\text { unchanged compared to the controls. }\end{array}$ \\
\hline $\begin{array}{l}\text { Nakamae et al. } \\
\text { [95] }\end{array}$ & Valsartan (80 mg) & $40(20 / 20)$ & 7 days & Echo & $\begin{array}{l}\text { Valsartan significantly inhibited the dilatation of } \\
\text { LVDd }(P=0.01) \text {, elevation of BNP }(P=0.001) \text {, and } \\
\text { prolongation of the QTC interval and QTC } \\
\text { dispersion ( } P<0.001 \text { and } P=0.02 \text {, respectively) }\end{array}$ \\
\hline $\begin{array}{l}\text { Georgakopoulos } \\
\text { et al. [97] }\end{array}$ & $\begin{array}{l}\text { Metoprolol d vs. enalapril }{ }^{d} \text { vs. } \\
\text { placebo }^{\mathrm{e}}\end{array}$ & $\begin{array}{l}125(42 / 43 / \\
40)\end{array}$ & 31 (Longest 36) & Clinical & $\begin{array}{l}\text { Cardiotoxicity incidence: } \\
\text { Metoprolol: } 1 \text { vs. } 3 \text {, not significant } \\
\text { Enalapril: } 2 \text { vs. } 3 \text {, not significant } \\
\text { No difference in echocardiographic variables } \\
\text { among } 3 \text { groups at } 12 \text { months } \\
\text { Comments: } \\
\text {-Results published as a letter not full article } \\
\text {-Appears to be a cohort study, not a randomized } \\
\text { trial }\end{array}$ \\
\hline
\end{tabular}


Table 1 Summary of studies for primary prevention of anthracycline-induced cardiotoxicity with beta-blockers, angiotensinconverting enzyme inhibitors, angiotensin receptor blockers, and aldosterone antagonists (Continued)

\begin{tabular}{|c|c|c|c|c|c|}
\hline Reference & Medications & $\begin{array}{l}\text { Patients } \\
\text { (groups), } \mathrm{N}^{\mathrm{a}}\end{array}$ & $\begin{array}{l}\text { Follow-Up, } \\
\text { mean (SD) Months }\end{array}$ & $\begin{array}{l}\text { Imaging } \\
\text { Modality }\end{array}$ & Results by group \\
\hline & & & & & -Cardiotoxicity not defined \\
\hline Bosch et al. [11] & $\begin{array}{l}\text { Enalapril }(8.6[5.9] \mathrm{mg})+ \\
\text { Carvedilol }(23.8[17] \mathrm{mg}) \\
\text { vs. no treatment }\end{array}$ & $90(45 / 45)$ & 6 & $\begin{array}{l}\text { Echo and } \\
\text { CMR }\end{array}$ & $\begin{array}{l}\text { Enalapril + carvedilol: LVEF } 63.3 \% \rightarrow 62.9 \% \\
\text { Control: LVEF } 64.6 \% \rightarrow 57.9 \%+c T n l \text { concentrations } \\
\text { did not differ between } 2 \text { groups }(P=0.59)\end{array}$ \\
\hline Gulati et al. [12] & $\begin{array}{l}\text { Candesartan }(32 \mathrm{mg})^{\mathrm{g}}+ \\
\text { metoprolol }(100 \mathrm{mg}) \text { vs. } \\
\text { Candesartan }+ \text { placebo vs. } \\
\text { Metoprolol }{ }^{\mathrm{g}}+\text { placebo vs. } \\
\text { Placebo + placebo }\end{array}$ & $\begin{array}{l}126(30 / 32 / \\
32 / 32)\end{array}$ & 10-61 weeks & CMR & $\begin{array}{l}\Delta \text { LVEF from baseline } \\
\text { 1. Candesartan: }-0.8 \text { vs. }-2.6 \%, P=0.023 \\
\text { 2. Metoprolol: }-1.6 \text { vs. }-1.8 \%, P=0.77 \\
\text { Data were analyzed differently (comparing all } \\
\text { those who received a drug to those who did not) } \\
\text { from factorial design of the trial. }\end{array}$ \\
\hline $\begin{array}{l}\text { Akpek et al. } \\
\text { [104] }\end{array}$ & Spironolactone ${ }^{\mathrm{h}}$ vs. placebo & $83(43 / 40)$ & $24.0[2.9]$ weeks & Echo & $\begin{array}{l}\text { Spironolactone LVEF } 67 \% \rightarrow 65.7 \%(P=0.094) \\
\text { Placebo LVEF } 67.7 \% \rightarrow 53.6 \%(P<0.001) \\
\text { Troponin and NT-proBNP remained in normal } \\
\text { limits. } \\
\text { Increase in the control group was more than in } \\
\text { the spironolactone group }\end{array}$ \\
\hline $\begin{array}{l}\text { Gupta et al. } \\
\text { (PEDIATRIC) } \\
{[105]}\end{array}$ & Enalapril' vs. placebo & $84(44 / 40)$ & 6 & Echo & $\begin{array}{l}\text { Enalapril LVEF } 65.73 \% \rightarrow 62.25 \% \\
\text { Placebo LVEF } 64.85 \% \rightarrow 56.15 \%+ \\
>20 \% \text { decrease in LVEF: } \\
\text { Enalapril - } 0 \\
\text { Placebo- } 3 \text { patients }(8 \%) \\
\text { Higher proBNP in placebo group }(P<0.001) \\
\text { Higher cTnl level in placebo group }(P=0.035)\end{array}$ \\
\hline $\begin{array}{l}\text { El-Shitany et al. } \\
\text { (PEDIATRIC) } \\
{[106]}\end{array}$ & Carvedilol ${ }^{\mathrm{j}}$ vs. control & $50(25 / 25)$ & $\begin{array}{l}\text { After last } \\
\text { doxorubicin dose }\end{array}$ & Echo & $\begin{array}{l}\text {-FS (2D) and GPSS (2DS) significantly increased in } \\
\text { carvedilol treated group. } \\
\text {-Carvedilol pretreatment inhibited ADR-induced } \\
\text { increase in plasma troponin I and LDH. (Post } \\
\text { treatment troponin, } 0.061 \text { vs. } 0.023, P \leq 0.05 \text {. } \\
\text { Post treatment, LDH } 957 \text { vs. } 410, P \leq 0.05 \text { ) }\end{array}$ \\
\hline
\end{tabular}

LVEF, left ventricular ejection fraction; cTnl, cardiac troponin I; FS (2D), fractional shortening measured by 2-dimensional echocardiography; CK-MB, creatine kinase$\mathrm{MB} ; \mathrm{E} / \mathrm{e}^{\prime}$ ratio, early mitral inflow velocity: mitral annular early diastolic velocity ratio; GPSS (2DS), global peak-systolic strain measured by 2 -dimensional echocardiography; ADR, doxorubicin; LDH, lactate dehydrogenase

† Statistically significant between baseline and 6 months $(P<0.05)$

${ }^{a}$ Numbers in parentheses are the numbers of patients in intervention and control or placebo groups, respectively

b Carvedilol $6.25 \mathrm{mg}$ daily during chemotherapy

c $12.5 \mathrm{mg}$ oral carvedilol daily for 6 months during chemotherapy

${ }^{\mathrm{d}}$ Medications titrated as tolerated

${ }^{\mathrm{e}}$ Medications started on the first day of chemotherapy and continued throughout the study

${ }^{\mathrm{f}}$ Medications started within 1 week before the first chemotherapy cycle and continued for 6 months

${ }^{9}$ Starting dose was $8 \mathrm{mg}$ for candesartan cilexetil and $50 \mathrm{mg}$ for metoprolol succinate; target dose 32 and $100 \mathrm{mg}$, respectively

${ }^{\mathrm{h}}$ Dose was $25 \mathrm{mg} /$ day started 1 week before the start of chemotherapy until 3 weeks after end of chemotherapy

'Dose was $0.1 \mathrm{mg} / \mathrm{kg} /$ day once a day from the first day of chemotherapy for 6 months

${ }^{\mathrm{j}}$ Starting carvedilol dose was $0.1 \mathrm{mg} \mathrm{kg}{ }^{-1} \mathrm{~d}^{-1}$ in two divided doses, increased weekly until reaching a dose of $1 \mathrm{mg} / \mathrm{kg}$ before the last dose of doxorubicin

$(n=40)$ before each doxorubicin dose [88]. Echocardiograms obtained 1 week after completing doxorubicin therapy revealed that LV strain and strain-rate in the women receiving carvedilol were closer to normal than were those in women receiving placebo, but mean LVEF did not differ significantly between groups [88]. No longer-term data were provided, and the differences in clinical outcomes were not reported.

A fourth randomized trial, that evaluated carvedilol in 80 women with breast cancer, had similar findings. Ventricular function, as measured by 2D-speckle tracking strain echocardiography, was better in women receiving carvedilol than in those receiving placebo after 6 months of follow-up [89]. However, the control group did not differ in any other cardiac measurements (LVEF, LVFS, or LV size) from the carvedilol group or in clinical cardiac endpoints (no patients in the trial in either group experienced a clinical cardiac event).

Another study of 54 patients tested the efficacy of carvedilol as primary prevention for doxorubicin-induced cardiomyopathy [90]. At 6 months of follow-up, LV systolic function, as measured by mean LVEF and LVFS on echocardiography, was slightly higher in the carvedilol group than in the control group (LVEF, 63.88\% versus $60.82 \%$, no $P$ value was provided). Interestingly, mean LVEF and LVFS in the carvedilol group were marginally higher after treatment than before treatment. Further, the within-group differences between 6 month followup and baseline were not compared statisically between groups. 
In a meta-analysis of carvedilol for preventing anthracycline-induced cardiotoxicity ( 8 RCTs, 633 pooled patients), the incidence of low LVEF was significantly lower in the carvedilol group (3.2\% versus $5.8 \%$; odds ratios [OR], $0.42 ; 95 \% \mathrm{CI}, 0.18$ to $0.99 ; P=0.05$ ) [91]. The authors concluded that prophylactic carvedilol in patients undergoing anthracycline treatment may reduce the incidence of LV dysfunction. However, the trials in the study had only short-term follow-ups.

Another BB, nebivolol, was also investigated in a small RCT of women with breast cancer undergoing chemotherapy in which 27 received nebivolol, $5 \mathrm{mg}$ daily, and 18 received placebo [92]. After 6 months, echocardiographic measurements of LV dimensions had increased, indicating worsening, in the placebo group $(P=0.01)$ but remained unchanged in the nebivolol group $(P=0.93)$. The placebo group also had a lower mean (SD) LVEF than that of the nebivolol group (57.5\% [5.6\%] versus 63.8 [3.9\%], respectively; $P=0.01$ ) at follow-up, although the values were about equal at baseline. Serum concentrations of NT-proBNP did not change in the nebivolol group $(P=0.77)$, but they were increased in the placebo group $(P=0.01)$ [92]. The study did not report any differences in the incidence of clinical events.

Angiotensin inhibitors and receptor blockers A few trials have evaluated an ARB or an ACEI for preventing anthracycline-associated cardiac dysfunction. The multicenter phase III ICOS-ONE (International CardioOncology Society-ONE) trial compared patients randomly assigned to receive enalapril at the start of chemotherapy (the prevention group) with those in whom enalapril was started only after serum troponin concentrations increased (the troponin-triggered group) [93]. The incidence of troponin elevations peaked 1 month after chemotherapy and was similar in both groups: $26 \%$ (31/ $136)$ in the prevention and $23 \%(36 / 137)$ in the troponin-triggered group. However, after 12 months, cardiotoxicity, defined as 10-percentage-point reduction in LVEF, with values $<50 \%$, developed in only 3 patients, 2 in the prevention group and 1 in the troponintriggered group. Because the outcomes did not differ, the authors recommended the troponin-triggered treatment strategy as more convenient [93].

An RCT of 69 patients receiving enalapril or placebo with anthracycline chemotherapy found no difference in mean LVEF at 6 months, although patients in the control group had significantly lower LVEF at the end of the follow-up period compared with their baseline values (LVEF: $46.31 \pm 7.04$ versus $59.61 \pm 5.7 \%$ respectively; $P<$ 0.001) [94]. This study also found that serum cTnI and creatine kinase-MB concentrations were significantly higher in the control group than in the enalapril group, suggesting some cardioprotective effect of enalapril against anthracycline-induced cardiotoxicity [94]. However, the study did not report any differences in clinical outcomes.

Another RCT evaluating only an ARB investigated the potential cardioprotective effect of valsartan in 40 patients with non-Hodgkin lymphoma treated with cyclophosphamide, doxorubicin, vincristine, and prednisone (the CHOP regimen) [95]. Valsartan significantly inhibited LV dilation $(P=0.01)$, elevations in BNP concentrations $(P=0.001)$, prolongation of the QTc interval, and QTc dispersion $(P<0.001$ and $P=0.02$, respectively) after chemotherapy. However, follow-up was only 1 week after initiating chemotherapy [95].

In a similar study, the same investigators randomly assigned 91 women recently diagnosed with breast cancer and treated with anthracyclines to either carvedilol or placebo and evaluated changes in LVEF 6 months after diagnosis [96]. Median reduction in LVEF from baseline was $10 \%$ in the placebo group and zero in the carvedilol group $(P<0.001)$ [96]. In addition, 30 days after therapy started, median cTnI concentration and the incidence of cTnI concentrations $>0.05 \mathrm{ng} / \mathrm{mL}$ were higher in the placebo group (48.6\% versus $24.4 \% ; P=0.03$ ) [96].

One study, published as a letter, without full methodologic details [97], compared an ACEI (metoprolol) versus $\mathrm{BB}$ (enalapril) versus no medication as primary prevention against anthracycline cardiotoxicity in 125 adults with lymphoma. Neither clinically important HF (which occurred in only 6 patients) nor changes in subclinical echocardiographic measures differed by group.

A few trials have investigated the efficacy of drug combinations in preventing chemotherapy-induced cardiotoxicity. In 90 patients with newly diagnosed or relapsed hematological malignancies (the OVERCOME Trial), patients treated with an ACEI (enalapril) and a BB (carvedilol) had smaller reductions in LVEF than those in untreated controls during the 6 months of observation [11]. In this study, mean LVEF, as measured by echocardiography, decreased by $3.11 \%$ in the 37 controls and by $0.17 \%$ in the intervention group $(P=0.04)$. The difference in clinical cardiac events was not reported separately, but only 2 patients experienced symptomatic HF [11]. Subsequently, a randomized, placebo-controlled, double blind trial was conducted in 120 women with breast cancer receiving post-surgery adjuvant chemotherapy with epirubicin, 5-fluorouracil, and cyclophosphamide [12]. Women were randomly assigned to one of four groups: candesartan alone, metoprolol alone, both medications, and placebo. Cardiac function was monitored with serial transthoracic echocardiograms and cMRI scans before and after cancer treatment. Scans were acquired at baseline, after the first and the final cycles of anthracycline therapy, and after trastuzumab or radiation therapy was completed. Although the 
candesartan group had a smaller mean decline in LVEF than did the placebo group $(0.8 \%$ versus $2.6 \%, P=0.03)$, metoprolol showed no evidence of being cardioprotective because the decline in LVEF was identical to that in the placebo group [12]. However, the data were analyzed by comparing all those who received any drug to those who did not, as opposed to testing the factorial design of how the medications were assigned. Thus, it was not a true test of the efficacy of combining two medications.

Among 6542 women ( $\geq 66$ years old) newly diagnosed with breast cancer and identified from two populationbased data sources, treatment with ACEIs or BBs was assessed as the number of prescriptions filled before or after the start of trastuzumab or anthracycline therapy. The adjusted hazard ratio for cardiotoxicity and allcause mortality was 0.77 ( $95 \% \mathrm{CI}, 0.62$ to 0.95$)$ in the ACEI group and 0.79 (95\% CI, 0.70 to 0.90 ) in the $\mathrm{BB}$ group, compared to the hazards in the non-exposed (to either ACEI or BB) group. Starting ACEIs/BBs $\leq 6$ months after the initiation of trastuzumab/anthracyclines and having exposed duration of $\geq 6$ months were associated with decreased risk of cardiotoxicity and allcause mortality [98]. Although suggesting a clinical benefit, the results are from an observational study and cannot be attributed to specific medications or drug classes or to primary, secondary, or tertiary prevention.

A meta-analysis of 14 studies (12 RCTs and 2 observational studies; 2015 pooled patients) reviewed the efficacy of several drugs for the primary prevention of chemotherapyinduced cardiotoxicity [99]. The data did not include the incidence of clinical events (e.g., hospitalizations or death from HF) and effects $>1$ year [99]. The analysis did find that angiotensin antagonists $(P<0.001)$ and BBs $(P<0.001)$ prevented short-term chemotherapy-induced cardiotoxicity. However, the decreased reduction in LVEF does not necessarily mean these drugs prevented primary damage to cardiomyocytes from anthracyclines. An alternative, and more likely, explanation is that these drugs attenuated the decrease in LVEF by lowering systemic vascular resistance. Only one study in the meta-analysis, a large, single-center retrospective cohort study, considered clinical events occuring more than a year postchemotherapy. At a median of 3.2 years after diagnosis, the 106 women with breast cancer treated with an anthracyclines, transtuzumab, or both who were taking BBs throughout treatment, had an $80 \%$ lower risk of hospitalization for HF compared to the 212 women on similar chemotherapeutic regimens who did not receive BB [100].

Aldosterone antagonists Mineralocorticoid receptor antagonist blockade, such as that provide by potassiumsparing diuretics, suppresses fibrosis and improves clinical outcomes in patients with chronic HF and after myocardial infarction and supports the efficacy of aldosterone signaling in extra-renal organs [58].

In six rats, spironolactone prevented pathophysiological alterations secondary to doxorubicin-like prolongation of the QTc interval, decreased LVEF and LVFS, and increased LV end-diastolic and end-systolic dimensions $(P<0.05)$ [101]. In another study of 80 rats, although spironolactone was cardioprotective, as assessed by microscopic evidence of cardiac inflammation and fibrosis, it had no protective effect on the thoracic aorta (with respect to inflammation, fibrosis and TGF- $\beta$ expression) when administered with radiotherapy and trastuzumab [102].

The effect of mineralocorticoid receptor activity and its potential as a cardioprotectant during anthracycline therapy differs in animal and human studies, perhaps because of the variety of animal models and experimental methodology used to test cardioprotective activity [58]. The effects of anthracyclines in the laboratory can, but do not always, reproduce the clinically observed cardiotoxic effects in humans [103]. Because doxorubicin cardiotoxicity develops over months or years, the applicability of results obtained by compressing the time-toinjury by administering high doses of doxorubicin to animals to understanding the chronic in vivo situation in humans is highly questionable [58].

A randomized, double-blind, placebo-controlled study of 43 women with breast cancer receiving spironolactone ( $25 \mathrm{mg} /$ day) and 40 women on placebo treated concomitantly with doxorubicin or epirubicin suggested that spironolactone provided significant short-term cardioprotection [104]. Echocardiograms taken before chemotherapy and 3 weeks after chemotherapy showed that the decrease in LVEF was significantly less in the spironolactone group than in controls $(P<0.001)$ [104]. Similarly, LV diastolic functional grade was preserved in the spironolactone group $(P=0.10)$ but deteriorated in controls $(P<0.001)$. The study also noted that the incidence of elevated serum cardiac biomarker concentrations (creatine kinase-MB, cTnI, and NT-proBNP), total oxidative capacity, and the oxidative stress index were more pronounced in controls [104].

\section{Clinical studies in children}

Enalapril was evaluated as a cardioprotectant in a randomized, double blind, placebo-controlled trial of 41 children with leukemia and 43 with lymphoma who received anthracyclines (doxorubicin, daunorubicin, or both) at a cumulative dose of $\geq 200 \mathrm{mg} / \mathrm{m}^{2}$ [105]. The 44 children in the treatment group received enalapril, 0.1 $\mathrm{mg} / \mathrm{kg} / \mathrm{day}$, once a day from the first day of chemotherapy for 6 months; the remaining 40 children received a placebo. After 6 months, mean (SD) LVEF had decreased in both groups, but more so in the placebo group (62 [5] versus 56 [4]; $P<0.001)$. An absolute decrease in $\mathrm{EF} \geq$ 
$20 \%$ from baseline was seen in 3 patients in the placebo group but none in enalapril group $(P=0.21)$. Concentrations of proBNP $(P<0.001)$ and $\mathrm{cTnI}(P=0.04)$ were higher in the placebo group [105].

In another study of 50 children with acute lymphoblastic leukemia, pretreatment of ALL children with carvedilol for 5 days before every dose of ADR caused a significant $(P=.0015)$ increase $(14.9 \%)$ in FS measured 1 week after the last ADR dose compared with the values after ADR treatment [106]. Carvedilol pretreatment also significantly inhibited the expected doxorubicin-induced increases in plasma cTnI and LDH concentrations see in the placebo group, suggesting a cardioprotective effect of carvedilol [106].

Carvedilol pretreatment also significantly inhibited the expected doxorubicin-induced increases in plasma cTnI and LDH concentrations see in the placebo group, suggesting a cardioprotective effect of carvedilol [106].

In summary, studies using neurohormonal blocking drugs for primary prevention of HF are not conclusively positive and have several issues. Follow-up periods are limited, sample sizes in RCTs are small, and the results are often contradictory. Further, none of the randomized trials reported a difference in the frequency of clinical events. These limitations were acknowledged in a review of needed changes in this research: 1) the duration of therapy with these drugs and 2) medications need to be evaluated for their efficacy in preventing clinical endpoints, such as HF, and not simply for their effect on surrogate endpoints, such as measures of subclinical cardiotoxicity [107]. It is important to determine whether lowering blood pressure and improving LVEF in these patients improves survival or other clinical outcomes [108, 109].

\section{Statins in primary prevention}

One of the most widely accepted mechanisms of anthracycline cardiotoxicity is the increase in reactive oxygen species [110-113]. Statins possess "pleiotropic effects"; they decrease oxidative stress and inflammation. Anthracyclines increase oxidative stress and inflammation and thus may potentially protect against anthracyclineinduced cardiac damage. In a propensity-matched cohort study, 67 women with newly diagnosed breast cancer treated with concomitant statins during anthracyclinebased chemotherapy had a lower risk of HF (HR, 0.3; 95\% CI, 0.1 to $0.9 ; P=0.03$ ) than the 134 women in the nonstatin-treated comparison group [114]. Average follow-up in this study was 2.6 years after diagnosis. Another study evaluated 51 patients receiving anthracycline-based chemotherapy for lymphoma, leukemia, or breast cancer with cMRI measurements acquired before cancer therapy and 6 months after the start of therapy. After adjusting for age, sex, diabetes, hyperlipidemia, and cumulative anthracycline dose, mean (SD) pre-post differences in LVEF were small in participants receiving a statin $(+1.1 \%$ [2.6\%]), whereas the difference in those not receiving a statin declined by $6.5 \%[1.5 \%] ; P=0.03)[115]$.

An RCT of prophylactic atorvastatin in 40 patients receiving anthracyclines found no significant difference from controls in the primary endpoint, the frequency of a LVEF $<50 \%$ after 6 months of treatment [116]. However, statin therapy resulted in a smaller decline in mean (SD) LVEF $(-1.3 \%$ [3.8\%] versus $-7.9 \%$ [8.0\%], $P<$ $0.001)$ and a lesser increase in mean LV end-systolic $(P<0.001)$ and end-diastolic $(P=0.02)$ dimensions in the treatment group. An ongoing RCT (the PREVENT study, clinical trial.gov; \#NCT01988571) is examining the cardioprotective effects of statin therapy in patients undergoing anthracycline-based chemotherapy. However, studies are necessary to determine whether any protective effects are truly related to statin therapy's pleiotropic effects, secondary to decreasing ischemic cardiomyopathy, or are the concomitant effects of neurohormonal antagonist prescriptions. In any case, adults with hypercholesterolemia or at increased risk of adverse cardiovascular events (a 10-year risk for heart disease or stroke $>7.5 \%$, as per the ACC/AHA heart risk calculator) should be treated appropriately with a statin [117].

In children, guidelines endorsed by the American Academy of Pediatrics recommend universal cholesterol screening in childhood [118]. Although these aggressive guidelines are well intended, their benefits and costeffectiveness have been questioned [119]. Almost 17\% of 2-to-19-year-old children were obese in 2012 [120]. Studies of obesity in cancer survivors have found similarly troubling trends, with one reporting that $13 \%$ of survivors were obese (body-mass index $>30$ ), and that another $28 \%$ were overweight, with a body-mass index between 25 and 30 [121]. Among 893 childhood cancer survivors in The Netherlands, only girls had a significantly higher incidence of obesity [122]. Another study of more than 200 survivors from the Pediatric LongTerm Survivor Clinic at the University of Rochester found that their mean LDL-cholesterol concentration was higher than that of 70 healthy siblings [123]. In a study of direct measurements of adiposity and comparisons to contemporary controls in 170 non-Hispanic white survivors and 71 sibling controls, body fat was greater in male survivors than in controls $(25.8 \%$ versus $20.7 \% ; P=0.007)$, as was trunk fat $(26.7 \%$ versus $21.3 \%$; $P=0.008$ ) [124]. These long-term survivors of childhood cancer also have an increased incidence of dyslipidemia, hypercholesterolemia, and hypertriglyceridemia [125-127].

Another study compared 156 survivors, either exposed or unexposed to anthracyclines and cardiac radiation, to 76 healthy sibling controls. Mean fasting serum concentrations of non-high-density lipoprotein cholesterol were 
higher in exposed survivors than in unexposed survivors and controls (126.5 and $121.1 \mathrm{mg} / \mathrm{dL}$, respectively, versus $109.8 \mathrm{mg} / \mathrm{dL}$ ), as were insulin concentrations (10.4 and $10.5 \mu \mathrm{U} / \mathrm{mL}$, respectively, versus $8.2 \mu \mathrm{U} / \mathrm{mL}$ ) [123]. Several epidemiological studies have reported an increased incidence of the metabolic syndrome and CVD in childhood cancer survivors [128].

These increased risk factors clearly predispose this group to future health problems. Although theoretically, statins may be cardioprotective in patients with several cardiovascular risk factors, the benefits and risks remain unclear in the absence of any long-term studies in these patients.

\section{Exercise in primary prevention}

Survivors of childhood cancers are more likely to be physically inactive than their siblings and less likely to meet recommended physical activity guidelines $[129,130]$. In a study of 72 survivors of childhood cancers with a mix of diagnoses but of similar age and receiving similar chemotherapeutic drugs, at a mean of 13.4 years after their cancer diagnosis (range, 4.5 to 31.6 years), survivors had significantly lower exercise capacity $\left(\mathrm{VO}_{2}\right.$ max), less endurance (time to peak exercise), and lower anaerobic thresholds than did their 32 siblings [131]. Peak oxygen uptake $\left(\mathrm{VO}_{2} \max \right)$ during exercise testing was significantly reduced in $30 \%$ of survivors, [132] and the long-term exercise capacity and fitness level in these survivors were poor $[131,133]$. Cancer survivors often rank fatigue as their primary concern. A weight-loss trial in breast cancer survivors found that improvements in vitality were primarily associated with increases in physical activity rather than changes in body mass index [134]. Regular physical activity may also improve nutritional and cardiac conditions.

In a single-center, prospective study of 100 childhood cancer survivors with normal baseline LVEFs, after 10 years of follow-up, the LV and right ventricular systolic and diastolic myocardial responses to exercise were similar to those of 51 healthy controls [135].

Exercise training for breast cancer survivors is safe and has several physiological and psychological benefits [136]. Some groups have recommended that cancer survivors engage in moderate aerobic exercise $150 \mathrm{~min} /$ week or vigorous aerobic exercise $75 \mathrm{~min} /$ week [136, 137]. A recent meta-analysis of the benefit of exercise in cancer patients and survivors further refined this recommendation and concluded that although exercise should be encouraged for most cancer patients, targeting specific subgroups may be more beneficial and cost effective [138]. In breast cancer survivors, exercise prescriptions based on heart rate reserve are too intense, and those based on $\mathrm{VO}_{2}$ max are slightly less intense than optimal. The study found that the recommended percentages for maximal heart rate appear valid [137].
Survivors of childhood cancer should be encouraged to exercise regularly to improve exercise capacity, weight, mental status, and cardiometabolic risk [131]. However, survivors with certain characteristics, such as restrictive cardiomyopathy, should be closely monitored because unsupervised exercise puts them at risk for pulmonary congestion and arrhythmias [131, 139].

Whether physical conditioning and rehabilitation programs are potentially detrimental to some survivors or help only a subset needs to be determined. For safety, exercise prescriptions should be based on the condition of the individual patient, rather than for a group of survivors, and should be periodically reevaluated because survivors' health changes over time [131, 139]. Hopefully, appropriate and safe increases in physical activity will decrease survivors' cardiovascular risk [129, 140]. A recent Scientific Statement from the American Heart Association promotes the use of cardiac rehabilitation to provide structured exercise to cancer patients and survivors [141]. This AHA Scientific Statement also discusses the need for research to fully develop and implement a multimodal model of the cardio-oncology rehabilitation.

\section{Secondary prevention of anthracycline-induced cardiotoxicity}

Managing asymptomatic anthracycline cardiotoxicity and preventing symptoms, as well as florid HF and death, is the definition of secondary prevention. There are no evidence-based guidelines for monitoring cardiotoxicity during and after anticancer therapies in adults or children. Although expert consensus guidelines have been published, the efficacy of specific regimens has not been determined, and recommendations from different groups are not consistent $[20,142]$. This lack of evidence, even for screening, as well as inconsistent recommendations, are the first challenges for clinicians in attempting secondary prevention.

\section{Neurohormonal blocking drugs and implantable devices Preclinical studies}

In a rabbit model of doxorubicin cardiotoxicity, metoprolol did not change or reduce the frequency or severity of arrhythmias, in contrast to treatment with carvedilol, which reduced the arrhythmic risk of anthracycline cardiotoxicity [143].

\section{Clinical studies in adults}

The most accepted current efforts in cardioprotection relate to recognizing early impaired LV function, which allows early interventions, such as administering a drug to attenuate or reverse the effect. The European Society for Medical Oncology clinical practice guidelines recommend that all adult cancer patients with HF and an LVEF $<40 \%$ be treated with ACEIs in combination with 
a $\mathrm{BB}$, unless specifically contraindicated. According to Strength-of-Recommendation Taxonomy [SORT] criteria, this recommendation is based on the best-quality evidence: level 1, grade A) [20]. However, these recommendations are based largely on cardiology practice in the general population and on only a few small studies examining the utility of these drugs in cancer patients and survivors.

A retrospective study of 10 adults with anthracyclineinduced cardiomyopathy (an LVEF of $\leq 45 \%$ ) found an early benefit of the $\mathrm{BB}$, metoprolol, when compared to 16 age-and-sex-matched controls with idiopathic dilated cardiomyopathy also receiving BBs [144]. The mean pretreatment LVEF of $28 \%$ improved to $41 \%(P=0.04)$ in the 10 patients at an average of 8 months after beginning treatment with metoprolol [144].

In an RCT, 114 cancer patients with elevated serum cTnI concentrations were randomly assigned to either enalapril $20 \mathrm{mg} /$ day or to no treatment for 1 month after high-dose chemotherapy [145]. After 12 months, cardiotoxicity (defined as an absolute decrease to $<50 \%$ or a decrease of $\geq 10 \%$ in resting LVEF from baseline) was detected in 25 of 58 patients not receiving enalapril but in none of 56 patients treated with enalapril [145]. In addition, the cumulative number of adverse cardiac events (sudden death, death from a cardiac cause, acute pulmonary edema, overt HF, and life-threatening arrhythmias requiring treatment) in patients treated with enalapril was much lower than that in controls, with HF itself occurring in 0 and $24 \%(P<0.001)$ in each group respectively [145].

The International Cardio Oncology Society-ONE study, mentioned above, compared the effects of enalapril for primary prevention of cardiotoxicity to its effect in secondary prevention (when administered after a rise in troponin concentrations) [93]. The two enalapril treatment strategies did not differ in their ability to prevent myocardial injury, as detected by increases in troponin concentrations, leading the authors to advocate enalapril for secondary prevention [93].

Whether BBs or ACEIs truly attenuate anthracyclineassociated cardiotoxicity has not been established. Although some short-term responses are statistically significant, these could be due to the hemodynamic effects of afterload reduction and true "prevention" of cardiotoxicity may not have occurred. Longer follow-ups are necessary, as is identifying the primary mechanism of cardiotoxicity. The causes of the endpoints are confounded by other factors, making it impossible for any of these studies to truly represent "primary prevention."

A prospective study of 201 consecutive patients (mean [SD] age, 53 [12] years; 149 women) with anthracyclineinduced cardiomyopathy (LVEF $\leq 45 \%$ ), with or without HF (74\% of patients in NYHA functional class I or II), found that early administration of enalapril, and when possible carvedilol, was associated with better LVEF recovery and fewer cardiac events during the mean (SD) follow-up period of 36 (27) months; range, 12 to 96 months [146]. Responders to cardioprotective therapy, defined a complete recovery of LVEF, had lower rates of cumulative cardiac events (sudden death, cardiac death, acute pulmonary edema, HF requiring hospitalization, life-threatening arrhythmias, and conduction disorders requiring pacemaker implantation) than did partial (some recovery of LVEF) and non-responders (no recovery of LVEF): 5 , 31, and 29\%, respectively $(P<0.001)$ [146].

In the only known RCT to date, prophylactic implantation of cardioverter-defibrillators for primary prevention of sudden cardiac death has not benefited patients with non-ischemic cardiomyopathy (LVEF $\leq 35 \%$ ) and symptomatic systolic HF, in contrast to the successes in patients with ischemic-cardiomyopathy [147]. This result challenges the utility of these devices in patients with chemotherapy-induced cardiomyopathy. It should be noted that $58 \%$ of patients in this trial received cardiac resynchronization therapy. In contrast, a small, single-center study of 18 consecutive patients with anthracycline-induced cardiomyopathy reported improvements in echocardiographic measurements and clinical benefit with cardiac resynchronization therapy not seen in patients with non-ischemic cardiomyopathy [148]. However, the data is limited. An ongoing multicenter, non-randomized, prospective observational study, the Multicenter Automatic Defibrillator Implantation Trial - Chemotherapy-Induced Cardiomyopathy (MADIT-CHIC; NCT02164721), is testing the effectiveness of resynchronization therapy in this population with a target enrollment of 100 patients.

\section{Clinical studies in children}

Only two RCTs have evaluated the use of medications to prevent asymptomatic cardiotoxicity in childhood cancer survivors from progressing to clinically evident cardiotoxicity, though multiple case series have been reported. In three children with congestive HF after receiving doxorubicin, metoprolol improved symptoms and echocardiographic measurements of LV structure and function over 5 to 30 months [149]. In another case series, 22 childhood cancer survivors (median age, 14.8; range 6.4 to 21.6 years), echocardiograms acquired before and during therapy with ACEs or ARBs were analyzed retrospectively with two-dimensional speckle tracking [150]. Mean global longitudinal strain $(P=0.002)$, global circumferential strain $(P=0.03)$, longitudinal strain rate $(P=0.02)$, and circumferential strain rate $(P=0.03)$ improved on therapy. Improvement was maintained for $>$ 1 year on ACEI or ARB $(P=0.02)$ [150]. However, the indications for administering ACEIs or ARBs were not 
given, so the number of patients in whom cardiac symptoms actually prompted therapy is unknown.

In a review of 18 childhood cancer survivors with symptomatic and asymptomatic anthracycline-associated cardiomyopathy, enalapril temporarily improved LV structure and function [151]. However, enalapril did not prevent disease progression; it merely delayed it for 6 to 10 years for patients with asymptomatic LV dysfunction at the start of treatment before returning to baseline [151]. For enalapril-treated patients with HF on this study, the benefit was only for 2 to 6 years. All 6 patients with HF progressed to cardiac transplantation or cardiac death within 2 to 6 years. Enalapril also did not prevent progressive LV wall thinning, the primary defect that increases LV afterload and decreases LVFS in survivors of childhood cancer [151]. In other words, enalapril did not address the primary defect of an inappropriately thin LV wall, it just reduced LV afterload secondary to a shortterm lowering of diastolic blood pressure and LV dilation [151].

Many clinicians have justified using ACEIs for secondary prevention in childhood cancer survivors with the results of the ACEI After Anthracycline (AAA) trial. This RCT of enalapril in 146 childhood cancer survivors had only one significant finding: a reduction in LV endsystolic stress in the first year of therapy, which was entirely attributable to a reduction in blood pressure attributed to ACEIs $(P=0.04)$ [152]. However, enalapril was associated with a significantly higher risk of dizziness or hypotension (RR, 7.17; 95\% CI, 1.71 to 30.17) and fatigue $(P=0.01)$ [152].

A Cochrane review found two randomized trials evaluating medical interventions for anthracycline-induced cardiotoxicity in childhood cancer survivors [153]. One was the ACEI After Anthracycline (AAA) study mentioned above, and the other was a study comparing 2 weeks of treatment with phosphocreatine against controls not receiving phosphocreatine. The authors concluded that, although enalapril may temporarily improve LV function, whether it improves long-term clinical outcomes was unclear [153].

The Children's Oncology Group is currently studying the effects of a 2-year course of carvedilol in an RCT of 250 childhood cancer survivors diagnosed before age 21 years and previously treated with high cumulative doses of anthracyclines $\left(\geq 300 \mathrm{mg} / \mathrm{m}^{2}\right)$ [154]. The primary objective is to determine the effect of carvedilol on echocardiographic measures of cardiac remodeling and the risk of HF, including the LV wall thickness:dimension ratio, LVEF, LV volume, and serum biomarker concentrations (natriuretic peptides, galectin-3) that are associated with increased risk for HF.

The studies reviewed above, with medications such as BBs, ACEIs, and ARBs given for primary or secondary prevention, may show occasional short-term improvements in LVEF. However, no studies have found long-term differences in clinical outcomes. In contrast, evidence-supported cardioprotective therapies, such as dexrazoxane, started before and maintained during chemotherapy, allow life-saving chemotherapies to be administered while limiting adverse cardiovascular events.

\section{Non-anthracycline anti-neoplastic drugs (targeted therapy and immunotherapy)}

In the past two decades, a better understanding of the molecular pathways involved in tumor progression has led to more selective, mechanism-based therapies [155]. An explosion of new cancer therapies has revolutionized therapy and markedly improved cancer prognosis. However, some of these therapies have an assortment of cardiovascular complications [156]. In addition, strategies for preventing these cardiotoxicities are not as well studied as are those for conventional therapies, such as anthracycline-induced cardiomyopathy.

\section{Problems with the long-term use of BETA-blockers}

Although historically, the long-term use of BBs was thought to decrease the risk of certain types of cancers by weakening norepinephrine signaling, the opposite may occur [157]. Additionally, BBs have displayed proangiogenic activity through a mechanism independent of their ability to antagonize catecholamine action. $\beta$ adrenergic receptor signaling facilitates VEGF-mediated angiogenesis [158]. This newly recognized signaling pathway is concerning because it may affect the prognosis of patients with solid cancers, in whom this signaling may facilitate tumor angiogenesis.

The mechanistic concerns about BBs have been apparent in at least three studies. At a median follow-up of 6.6 years, 8100 survivors of colorectal cancer showed no major improvements in survival after taking BBs [159]. In fact, a cumulative duration of treatment from 1 to 12 months was significantly associated with increased overall mortality (RR, 1.20; 95\% CI, 1.03 to 1.39 ) [159]. In a nationwide Danish cohort of 18,733 women treated for breast cancer, metoprolol was associated with increased recurrence rates (adjusted HR, 1.5; 95\% CI, 1.2 to 1.8 ) [157]. Finally, a population-based, case-control study revealed that the long-term (more than 6 years) use of BBs was associated with a significantly higher risk of stage IV colorectal cancer (OR, 2.02; 95\% CI, 1.25 to 3.27) [160]. However, BB use was not associated with the overall incidence of colorectal cancer, the primary outcome of the study [160]. Taken together, these studies suggest that long-term $\mathrm{BB}$ use in survivors has no adverse effects on cancer relapse or secondary cancers. However, these studies were not performed in survivors of childhood cancers, who are known to have an increased susceptibility to an 
oncologic relapse or the development of a secondary malignancy.

\section{Problems with long-term use of angiotensin receptor blockers and angiotensin converting enzyme inhibitors}

Studies have raised concerns about the long-term use of ARBs and ACEIs in cancer survivors. The Candesartan in Heart Failure Assessment of Reduction in Mortality and Morbidity (CHARM) study, that compared candesartan with placebo in patients with chronic HF, reported a $42 \%$ higher incidence of fatal neoplastic diseases during candesartan treatment [161]. In a meta-analysis of five trials with cancer recurrence as a pre-specified endpoint, the 61,590 pooled patients randomly assigned to receive ARBs had a significantly higher risk of new cancer occurrence than that of controls (RR, 1.11; 95\% CI, 1.04 to $1.18, P=0.001$ ) [162]. This meta-anaylsis concluded that ARBs are associated with a modestly increased (9\%) risk of new cancer diagnoses [162]. A second meta-analysis, performed 6 years later and including 19 studies (148,333 patients), also reported an 8\% higher risk of cancer with ARBs than with placebo, but not if the control group received an ACEI [163]. This result provides indirect evidence that ACEIs and ARBs both increase the risk of cancer when compared to placebo. Recently, the US Food and Drug Administration recalled the ARB losartan potassium hydrochlorothiazide over concerns that an impurity might be carcinogenic [164].

A cohort study found a higher incidence of basal and squamous cell carcinoma in patients with a documented order for an ACEI, ARB, or thiazide and no history of skin cancer [165]. The control group consisted of matched individuals from the same medical practice without documented exposure to these drugs. This potential higher cancer rate may be more of a concern to cancer survivors, who are already at increased risk for relapsed primary or secondary malignancies [166]. Indeed, the national Danish cohort of women with breast cancer revealed a small, but not statistically significant, increase in cancer recurrence with ACEI use (HR, 1.2; $95 \% \mathrm{CI}, 0.97$ to 1.4$)$. On the other hand, a meta-analysis of 14 trials with cancer data on 61,774 pooled patients found that ACEIs did not significantly affect the occurrence of cancer or cancer-related deaths in the general population [167].

In a population-based study of 992,061 patients newly treated with antihypertensive drugs over 20 years [167], ACEIs were associated with a higher risk of lung cancer than that in patients receiving ARBs (incidence rate, 1.6 versus 1.2 per 1000 person years, respectively; HR 1.14, 95\% CI; 1.01 to 1.29). Hazard ratios gradually increased with longer durations of use, with a statistically significant association evident after 5 years of use (HR, 1.22;
95\% CI, 1.06 to 1.40$)$ and peaking after more than 10 years of use (HR, 1.31; 95\% CI, 1.08 to 1.59) [168].

\section{Problems with the long-term use of aldosterone antagonists}

Aldosterone antagonists are associated with acute renal failure and hyperkalemia, both of which can be particularly challenging in patients undergoing cancer therapy, given their increased risk of kidney dysfunction and electrolyte imbalance in the setting of malignancy and chemotherapy. Non-selective drugs, such as spironolactone, have estrogenic effects that increase the risk of painful gynecomastia in up to $50 \%$ of patients [169]. Although spironolactone has been associated with a reduced incidence of prostate cancer [170], an increased risk of breast cancer with chronic use is a concern. However, convincing data from a retrospective cohort study of 1.3 million women followed for 4 years suggests that long-term management of cardiovascular conditions with spironolactone does not increase the risk of breast cancer [171].

\section{Discussion}

Neurohormonal antagonists are routinely used in adults with HF and are now being increasingly used-without strong evidence-in the fragile population of childhood and adult cancer survivors as a response to asymptomatic LV dysfunction without clinical HF (secondary prevention) as well as for primary prevention of cardiotoxicity $[31,58]$. The literature specific to using these medications to prevent anthracycline-associated LV dysfunction in both adults and children is limited. Most studies have small samples and short follow-ups, with some of the longest being 12 months after the end of therapy. Few studies, as mentioned above, have reported clinical events as a primary outcome and instead have used subclinical measures, albeit markers validated in the general population. Thus, the "success" of the primary prevention studies should be questioned [58, 93]. Another review concluded that studies with longer follow-ups tended to show that treatment with $\beta$-blockers and ACEI or ARBs do not prevent chemotherapy-induced cardiotoxicity [13].

Errors in equating LV dysfunction with myocardial damage may also be a factor in these studies. Alterations in LV function, identified as LV dysfunction, can often be secondary to a change in the loading conditions of the heart. Thus, changes in loading conditions do not always equate to myocardial damage and the "true effect" of the medications may be confounded. Results are also complicated by the fact that these studies tested several different dose schedules and age groups. Additionally, some trials and meta-analyses lacked rigorously defined clinical endpoints or used endpoints that combined 
subclinical findings and clinical events [58]. These studies show only a temporary improvement in LV echocardiographic variables and a lack of increase in cardiac biomarker concentrations, but no differences in the incidence of clinical events.

In contrast, some evidence indicates clinically beneficial effects of neurohormonal antagonist drugs, particularly ACEIs and BBs, administered for secondary prevention in patients with anthracycline-induced cardiomyopathy. In most of these studies, treatment with one or more neurohormonal antagonist was started in response to an asymptomatic elevation of cTnI concentrations or reduction in LVEF. Some studies suggest that the early introduction of cardioprotective therapy is associated with higher chances of LVEF recovery and fewer clinical cardiac events including, HF, arrhythmias, and death [146]. Although neurohormonal therapy is effective for secondary prevention after asymptomatic or subclinical cardiotoxicity develops, many non-specific symptoms are attributed to cancer and its treatment, even though they are often indistinguishable from those of clinical HF, meaning that many patients may be misclassified. No study of ACEIs, ARBs, aldosterone antagonists, or BBs in survivors of adult cancers has reported persuasive evidence that these drugs improve survival or quality-of-life when used for either primary or secondary prevention.

Even fewer studies have addressed the use of BBs or ACEIs in children. Any adverse effects of long-term therapy place survivors of childhood cancers at higher risk simply because of their markedly longer anticipated survival [109]. Patients using these medications longterm may also be at increased risk for other potential adverse events from these medications.

Although this lack of evidence may be explained by underpowered studies, the lack of benefit from standard heart failure medications may also be the result of fundamental differences between cardiomyopathy caused by chemotherapy-induced cardiotoxicity and that with other causes, such as ischemic, post-infectious, and idiopathic dilated cardiomyopathy [172]. The 10-year survival rate for pediatric cancers is now more than $80 \%$ [3]. Although these children are a small percentage of survivors, they have the longest potential life spans. Thus, preventing cardiotoxicity may be most important to them as individuals and as a population, especially considering the societal cost of medical care.

In long-term survivors of childhood cancers who have been treated with anthracyclines, the dominant clinical pattern is a progression from a dilated cardiomyopathy to a restrictive cardiomyopathy with increasing followup, whereas in contrast, adults treated with anthracyclines develop a chronic dilated, hypokinetic cardiomyopathy [173]. Restrictive cardiomyopathy is typically less responsive to the neurohormonal drugs used to treat other cardiomyopathies [109]. In most patients with dilated cardiomyopathy, ACEIs induce reverse-ventricular remodeling, reducing $L V$ volume and improving the LV mass-to-volume ratio, further reducing LV wall stress and improving LV function. In childhood cancer survivors with anthracycline-induced cardiomyopathy treated with ACEIs, ventricular remodeling in response to the fall in LV wall stress associated with afterload reducing agents is notably absent. In the two studies of children mentioned above [151, 152], despite a marked reduction in LV wall stress, LV size and thickness did not change. This lack of improvement is most likely caused by the minimal, non-progressive LV dilation in these patients, which is more characteristic of a restrictive cardiomyopathy, a disease class that does not benefit from ACEI therapy [172]. Further, many participants in the ACEI After Anthracycline (AAA) trial also received cardiac radiation, which is also associated with restrictive cardiomyopathy [152]. Admittedly, to what extent this restrictive predominance applies to survivors treated as adults is unclear. Yet, this predominance of restrictive cardiomyopathy does raise the concern that in adults, anthracyclinerelated cardiomyopathy is not the same as ischemic cardiomyopathy, as well as the concern that the neurohormonal blocking agents will not be effective [109].

Current data do not address whether the potential adverse effects of neurohormonal antagonists in patients with anthracycline-induced cardiomyopathy exceeds that in patients with other forms of dilated cardiomyopathy [109]. Thus, the wisdom of recommending medications based on the applicability of trials in other patient groups has been and should continue to be questioned [109]. Survivors of childhood cancers are at increased global risk for premature atherosclerotic heart disease, a risk that may also be affected by ACEI therapy [174]. Angiotensin converting enzyme inhibitors may cause fetal kidney abnormalities if taken during pregnancy, which may be a particular concern for female childhood cancer survivors [175].

The unknown effects of chronic neurohormonal suppression or other side effects of long-term BB therapy in this population are also a concern. Dizziness, hypotension, and fatigue were common problems for enalapril-treated participants in the ACEI After Anthracycline (AAA) trial and may be aggravated in this fragile population [152]. The considerable cost of an unproven, potentially life-long therapy, especially in young patients with large medical expenses and possible lifetime insurance limits, makes this therapy difficult to justify [109]. Potentially life-long medication use for asymptomatic patients also raises daily adherence issues. The potential for healthy, asymptomatic survivors to feel or be treated differently from their peers for taking chronic medications may increase the likelihood of these children feeling like "cardiac cripples" [109]. 
Therefore, we believe the evidence argues against routinely using these medications in patients with potential chemotherapy-induced cardiomyopathy, particularly for primary cardioprotection. Once subclinical or asymptomatic cardiotoxicity appear, as indicated by elevations in cardiac biomarker concentrations or as increases in global longitudinal strain or LVEF reduction without clinical HF, the decision to use neurohormonal antagonists for secondary prevention needs to be individualized after careful consideration of the patient's cardiac risk profile, type of anti-neoplastic therapy received, and personal preferences.

The above cautions notwithstanding, as in primary prevention, dexrazoxane may still be useful, even in secondary prevention. However, dexrazoxane should be compared to BBs, ACEIs, aldosterone antagonists, and ARBs in RCTs because quality-of-life remains paramount in long-term survivors, especially those with pre-existing risk factors.

Strategies to minimize cardiotoxicity during treatment are crucial to preventing lasting effects on health and quality-of-life. Because the long-term use of neurohormonal antagonists for primary or secondary prevention of cardiotoxicity in cancer patients and survivors has potential risks with unproven benefits, larger and longer clinical trials are needed to verify the efficacy and tolerability of these drugs. The short-term results in some of the studies reviewed could be used to justify further exploration of these drugs for cardioprotection in patients with cancer. However, longer, adequately powered, welldesigned clinical trials with clinical endpoints, including comparative analysis with existing effective medications, such as dexrazoxane, are required [176].

Arguably, one of the biggest challenges in the field of cardio-oncology is selecting appropriate endpoints. A single cardiology endpoint for a patient without symptomatic CVD is not likely to be as clinically meaningful as are oncologic, symptomatic CVD, or quality-of-life endpoints in this population. In children, studies using clinical endpoints, such as death, will likely be unable to detect efficacy because the time-to-event for these endpoints is decades long and thus are not feasible for prospective studies. Validated cardiac biomarkers should be incorporated into studies as surrogate endpoints when assessing reductions of anthracycline cardiotoxicity [58]. A combined "imaging-and-biomarker" approach has been suggested to increase the predictive value over that of a single indicator [18]. Finally, with all the side effects and potential risks of life-long use of these medications, recognizing that quality-of-life is an important end-point for these trials is important.

As the number of cancer survivors grow, particularly older patients with comorbid CVD receiving treatment for cancer, oncologists are increasingly reliant on $\mathrm{CV}$ specialists to risk-stratify and to address a myriad of comorbidities and the adverse effects of cancer therapeutics. Although the field of cardio-oncology is emerging at a fast pace, it is mainly restricted to a limited number of academic centers. To usher patients safely through cancer care, cardio-oncology care needs to expand simultaneously and hence training the next-generation of physicians in cardio-oncology is necessary [177].

\section{Conclusion}

Cardio-oncology is a broad, active, and new field of medicine. Here, we have summarized the strengths, weaknesses, opportunities, and threats in the field as identified in the most important published studies with special emphasis on the prevention of anthracyclineinduced cardiotoxicity.

Cancer and the resultant cardiotoxicity from both conventional and contemporary therapy substantially affect an increasing number of survivors. The optimal strategy for preventing and managing chemotherapy-induced cardiotoxicity remains unknown. We would contend that the routine use of neurohormonal antagonists for primary cardioprotection in this population is not currently justified, given only marginal benefits and associated adverse events, particularly with long-term use. Their use for secondary prevention in patients with subclinical cardiotoxicity should be individualized and carefully considered. On the other hand, dexrazoxane provides effective primary cardioprotection against anthracyclineinduced cardiotoxicity, and its use beyond the current FDA-approved indications should be investigated further. Longitudinal studies are needed to determine the prognostic value of subclinical markers of treatment-related cardiovascular injury on the long-term risk of CVD.

\section{Abbreviations}

ACEl: Angiotensin converting enzyme inhibitor; AHA: American Heart

Association; ARB: Angiotensin receptor blocker; BB: Beta-blocker; BNP: B-type natriuretic peptide; CMRI: Cardiac magnetic resonance imaging; CTNI: Cardiac Troponin I; CTnT: Cardiac Troponin T; CVD: Cardiovascular disease;

DCM: Dilated cardiomyopathy; EMA: European Medicines Agency; FDA: Food and Drug Administration; FS: Fractional shortening; HF: Heart failure; LV: Left ventricle; LVEF: Left ventricular ejection fraction; LVFS: Left ventricular fractional shortening; NT-proBNP: N-terminal B-type natriuretic peptide; $\mathrm{RCT}$ : Randomized controlled trial

\section{Acknowledgements}

None.

\section{Authors' contributions}

NB: Primary author of the manuscript. MJA: Expert review and extensive edits and revisions. SG: Expert review and extensive edits and revisions. SDC: Expert review and comments. S Agg: Expert review and comments. RS: Expert review and comments. S Am: Expert review and comments. ERL: Expert review and comments. SEL: Conceieved the paper, expert review, and extensive edits and revisions. All authors read and approved the final manuscript.

\section{Funding}

Dr. Lipshultz' work has been supported in part by grants from the National Institutes of Health (HL072705, HL078522, HL053392, CA127642, CA068484, HD052104, Al50274, CA127642, CA068484, HD052102, HD052104, HL087708, 
HL079233, HL004537, HL087000, HL007188, HL094100, HL095127, HD80002, HD028820), Pfizer, Roche Diagnostics, the Children's Cardiomyopathy Foundation, Sofia's Hope, Inc., the Kyle John Rymiszewski Foundation, the Children's Hospital of Michigan Foundation, the Scott Howard Fund, and the Michael Garil Fund.

\section{Availability of data and materials}

Not applicable.

\section{Ethics approval and consent to participate}

Not applicable (review article).

\section{Consent for publication}

Not applicable.

\section{Competing interests}

Rudolf Steiner: Oncology Consultant to Clinigen Group PLC, UK. Steven Lipshultz: Cardiology Consultant to Clinigen Group PLC, UK. Rest of the Authors: None.

\section{Author details}

'Division of Pediatric Cardiology, Children's Hospital at Montefiore, Bronx, NY, USA. ${ }^{2}$ Department of Public Health Sciences, University of Rochester School of Medicine and Dentistry, Rochester, NY, USA. ${ }^{3}$ Cardio-Oncology Program, Division of Cardiovascular Medicine, Department of Medicine, Lahey Hospital and Medical Center, Burlington, MA, USA. ${ }^{4}$ Cardio-Oncology Program, Dana-Farber Cancer Institute / Brigham and Women's Hospital, Boston, MA, USA. ${ }^{5}$ Department of Pediatric Cardiology, Boston Children's Hospital, Boston, MA, USA. 'Division of Pediatric Cardiology, Department of Pediatrics, Children's Hospital of Michigan, Detroit, MI, USA. University of Zurich, Zurich, Switzerland. ${ }^{8}$ Division of Pediatric Cardiology, Cleveland Clinic Children's Hospital, Cleveland, OH, USA. ${ }^{9}$ Dana-Farber Cancer Institute, Boston, MA, USA. ${ }^{10}$ University of Miami Miller School of Medicine, Miami, FL, USA.

${ }^{11}$ Department of Pediatrics, University at Buffalo Jacobs School of Medicine and Biomedical Sciences, Oishei Children's Hospital, 1001 Main Street, Buffalo, NY 14203, USA. ${ }^{12}$ Oishei Children's Hospital, Buffalo, NY, USA. ${ }^{13}$ Roswell Park Comprehensive Cancer Center, Buffalo, NY, USA.

Received: 2 May 2019 Accepted: 16 October 2019

\section{Published online: 02 December 2019}

\section{References}

1. Bluethmann SM, Mariotto AB, Rowland JH. Anticipating the "silver tsunami": prevalence trajectories and comorbidity burden among older Cancer survivors in the United States. Cancer Epidemiol Biomark Prev. 2016;25(7): 1029-36.

2. Couzin-Frankel J. Treatments for childhood cancer can devastate lives years later. Scientists are trying to change that. Science. https://www.sciencemag. org/news/2019/03/treatments-childhood-cancer-can-devastate-lives-yearslater-scientists-are-trying.

3. Armstrong GT, Chen Y, Yasui Y, Leisenring W, Gibson TM, Mertens AC, et al. Reduction in late mortality among 5-year survivors of childhood cancer. N Engl J Med. 2016;374(9):833-42.

4. Valcovici M, Andrica F, Serban C, Dragan S. Cardiotoxicity of anthracycline therapy: current perspectives. Arch Med Sci. 2016;12(2):428-35.

5. Ganatra S, Neilan TG. Immune checkpoint inhibitor associated myocarditis. Oncologist. 2018;23:518-23.

6. Mahmood SS, Fradley MG, Cohen JV, Nohria A, Reynolds KL, Heinzerling LM, et al. Myocarditis in patients treated with immune checkpoint inhibitors. J Am Coll Cardiol. 2018;71(16):1755-64.

7. Ganatra S, Sharma A, Shah S, Chaudhry GM, Martin DT, Neilan TG, et al. Ibrutinib-associated atrial fibrillation. JACC Clin Electrophysiol. 2018;4(12): $1491-500$.

8. Meijers WC, de Boer RA. Common risk factors for heart failure and cancer. Cardiovasc Res. 2019;115(5):844-53.

9. Moslehi JJ, Salem JE, Sosman JA, Lebrun-Vignes B, Johnson DB. Increased reporting of fatal immune checkpoint inhibitor-associated myocarditis. Lancet. 2018;391(10124):933.

10. Hunt SA, Abraham WT, Chin MH, Feldman AM, Francis GS, Ganiats TG, et al. 2009 focused update incorporated into the ACC/AHA 2005 guidelines for the diagnosis and Management of Heart Failure in adults: a report of the
American College of Cardiology Foundation/American Heart Association task force on practice guidelines developed in collaboration with the International Society for Heart and Lung Transplantation. J Am Coll Cardiol. 2009;53(15):e1-e90.

11. Bosch X, Rovira M, Sitges M, Domenech A, Ortiz-Perez JT, de Caralt TM, et al. Enalapril and carvedilol for preventing chemotherapy-induced left ventricular systolic dysfunction in patients with malignant hemopathies: the OVERCOME trial (preventiOn of left ventricular dysfunction with Enalapril and caRvedilol in patients submitted to intensive ChemOtherapy for the treatment of malignant hEmopathies). J Am Coll Cardiol. 2013; 61(23):2355-62.

12. Gulati G, Heck SL, Ree AH, Hoffmann P, Schulz-Menger J, Fagerland MW, et al. Prevention of cardiac dysfunction during adjuvant breast cancer therapy (PRADA): a 2 × 2 factorial, randomized, placebo-controlled, doubleblind clinical trial of candesartan and metoprolol. Eur Heart J. 2016;37(21): 1671-80.

13. Blanter JB, Frishman WH. The preventive role of ace inhibitors/angiotensin-ii receptor blockers and beta-adrenergic blockers in anthracycline and trastuzumab-induced cardiotoxicity. Cardiol Rev. 2019. https://doi.org/10. 1097/CRD.0000000000000252. Epub ahead of print.

14. Chow EJ, Leger KJ, Bhatt NS, Mulrooney DA, Ross CJ, Aggarwal S, et al. Pediatric cardio-oncology: epidemiology, screening, prevention, and treatment. Cardiovasc Res. 2019;115(5):922-34. https://doi.org/10.1093/cvr/ cvZ031.

15. Lipshultz SE, Sanders SP, Goorin AM, Krischer JP, Sallan SE, Colan SD. Monitoring for anthracycline cardiotoxicity. Pediatrics. 1994;93(3):433-7.

16. Colan SD, Lipshultz SE, Sallan SE. Balancing the oncologic effectiveness versus the cardiotoxicity of anthracycline chemotherapy in childhood cancer. Prog Pediatr Cardiol. 2014;36(1):7-10.

17. Lipshultz SE, Law YM, Asante-Korang A, Austin ED, Dipchand Al, Everitt MD, et al. Cardiomyopathy in children: classification and diagnosis. A scientific statement from the American Heart Association. Circulation. 2019;140(1):e9e68. https://doi.org/10.1161/CIR.0000000000000682.

18. Biasillo G, Cipolla CM, Cardinale D. Cardio-oncology: gaps in knowledge, goals, advances, and educational efforts. Curr Oncol Rep. 2017;19(8):55.

19. Cardinale D, Colombo A, Bacchiani G, Tedeschi I, Meroni CA, Veglia F, et al. Early detection of anthracycline cardiotoxicity and improvement with heart failure therapy. Circulation. 2015;131(22):1981-8.

20. Curigliano G, Cardinale D, Suter T, Plataniotis G, de Azambuja E, Sandri MT, et al. Cardiovascular toxicity induced by chemotherapy, targeted agents and radiotherapy: ESMO Clinical Practice Guidelines. Ann Oncol. 2012;23(Suppl 7):vii155-66.

21. Zamorano JL, Lancellotti P, Rodriguez Munoz D, Aboyans V, Asteggiano R, Galderisi M, et al. 2016 ESC position paper on cancer treatments and cardiovascular toxicity developed under the auspices of the ESC Committee for practice guidelines: the task force for cancer treatments and cardiovascular toxicity of the European Society of Cardiology (ESC). Eur J Heart Fail. 2017;19(1):9-42.

22. Vejpongsa P, Yeh ET. Prevention of anthracycline-induced cardiotoxicity: challenges and opportunities. J Am Coll Cardiol. 2014;64(9):938-45.

23. Lipshultz SE, Miller TL, Scully RE, Lipsitz SR, Rifai N, Silverman LB, et al. Changes in cardiac biomarkers during doxorubicin treatment of pediatric patients with high-risk acute lymphoblastic leukemia: associations with long-term echocardiographic outcomes. J Clin Oncol. 2012;30(10):1042-9.

24. Armenian SH, Lacchetti C, Barac A, Carver J, Constine LS, Denduluri N, et al. Prevention and monitoring of cardiac dysfunction in survivors of adult cancers: American Society of Clinical Oncology clinical practice guideline. J Clin Oncol. 2017;35(8):893-911.

25. Plana JC, Galderisi M, Barac A, Ewer MS, Ky B, Scherrer-Crosbie M, et al. Expert consensus for multimodality imaging evaluation of adult patients during and after cancer therapy: a report from the American Society of Echocardiography and the European Association of Cardiovascular Imaging. Eur Heart J Cardiovasc Imaging. 2014;15(10):1063-93.

26. Bonow $\mathrm{RO}$, Braunwald $\mathrm{E}$. The evidence supporting cardiovascular guidelines: is there evidence of progress in the last decade? JAMA. 2019;321(11):1053-4.

27. Bertero $E$, Ameri P, Maack C. Bidirectional relationship between cancer and heart failure: old and new issues in cardio-oncology. Card Fail Rev. 2019;5(2): 106-11.

28. Cardous-Ubbink MC, Geenen MM, Schade KJ, Heinen RC, Caron HN, Kremer LC, et al. Hypertension in long-term survivors of childhood cancer: a nested case-control study. Eur J Cancer. 2010;46(4):782-90. 
29. Bansal N, Amdani SM, Hutchins KK, Lipshultz SE. Cardiovascular disease in survivors of childhood cancer. Curr Opin Pediatr. 2018;30(5):628-38.

30. Krischer JP, Cuthbertson D, Epstein S, Goorin AM, Epstein ML, Lipshultz SE. Risk factors for early anthracycline clinical cardiotoxicity in children: the pediatric oncology group experience. J Clin Oncol. 1997 Apr;15(4):1544-52.

31. Bansal N, Amdani S, Lipshultz ER, Lipshultz SE. Chemotherapy-induced cardiotoxicity in children. Expert Opin Drug Metab Toxicol. 2017;13(8):817-32.

32. Armenian SH, Armstrong GT, Aune G, Chow EJ, Ehrhardt MJ, Ky B, et al. Cardiovascular disease in survivors of childhood cancer: insights into epidemiology, pathophysiology, and prevention. J Clin Oncol. 2018;36(21): 2135-44.

33. Nelson ER, Wardell SE, Jasper JS, Park S, Suchindran S, Howe MK, et al. 27hydroxycholesterol links hypercholesterolemia and breast cancer pathophysiology. Science. 2013;342(6162):1094-8.

34. Ahern TP, Pedersen L, Tarp M, Cronin-Fenton DP, Garne JP, Silliman RA, et al. Statin prescriptions and breast cancer recurrence risk: a Danish nationwide prospective cohort study. J Natl Cancer Inst. 2011;103(19): 1461-8.

35. Holmes MD, Chen WY, Feskanich D, Kroenke CH, Colditz GA. Physical activity and survival after breast cancer diagnosis. JAMA. 2005;293(20): 2479-86.

36. Banke A, Schou M, Videbaek L, Moller JE, Torp-Pedersen C, Gustafsson F, et al. Incidence of cancer in patients with chronic heart failure: a long-term follow-up study. Eur J Heart Fail. 2016;18(3):260-6.

37. McGowan JV, Chung R, Maulik A, Piotrowska I, Walker JM, Yellon DM. Anthracycline chemotherapy and cardiotoxicity. Cardiovasc Drugs Ther. 2017:31(1):63-75.

38. Bates JE, Howell RM, Liu Q, Yasui Y, Mulrooney DA, Dhakal S, et al. Therapyrelated cardiac risk in childhood cancer survivors: an analysis of the childhood cancer survivor study. J Clin Oncol. 2019 May 1;37(13):1090-101.

39. Lipshultz SE, Alvarez JA, Scully RE. Anthracycline associated cardiotoxicity in survivors of childhood cancer. Heart. 2008;94(4):525-33.

40. Bhakta N, Liu Q, Ness KK, Baassiri M, Eissa H, Yeo F, et al. The cumulative burden of surviving childhood cancer: An initial report from the St Jude lifetime cohort study (SJLIFE). Lancet. 2017;390(10112):2569-82.

41. Getz KD, Sung L, Ky B, Gerbing RB, Leger KJ, Leahy AB, et al. Occurrence of treatment-related cardiotoxicity and its impact on outcomes among children treated in the AAML0531 clinical trial: a report from the Children's oncology group. J Clin Oncol. 2019;37(1):12-21.

42. Mehta LS, Watson KE, Barac A, Beckie TM, Bittner V, Cruz-Flores S, et al. Cardiovascular disease and breast cancer: where these entities intersect: a scientific statement from the American Heart Association. Circulation. 2018; 137(8):e30-66.

43. Lipshultz SE, Adams MJ, Colan SD, Constine LS, Herman EH, Hsu DT, et al. Long-term cardiovascular toxicity in children, adolescents, and young adults who receive cancer therapy: pathophysiology, course, monitoring, management, prevention, and research directions: a scientific statement from the American Heart Association. Circulation. 2013;128(17):1927-95.

44. Boyle DA. Cancer and the broken heart: complications and implications of therapy-related cardiotoxicity. J Infus Nurs. 2018;41(4):229-40.

45. de Ferranti SD, Steinberger J, Ameduri R, Baker A, Gooding H, Kelly AS, et al. Cardiovascular risk reduction in high-risk pediatric patients: a scientific statement from the American Heart Association. Circulation. 2019;139(13): e603-e34.

46. Armenian $\mathrm{SH}$, Ehrhardt MJ. Optimizing cardiovascular care in children with acute myeloid leukemia to improve cancer-related outcomes. J Clin Oncol. 2019;37(1):1-6.

47. US Food and Drug Administration. Orphan drug designations and approvals https://www.accessdata.fda.gov/scripts/opdlisting/oopd/detailedlndex. cfm?cfgridkey $=441314$.

48. European Medicines Agency. Assessment report dexrazoxane-containing medicinal products. http://www.ema.europa.eu/docs/en_GB/document_ library/Referrals_document/Dexrazoxane_31/WC500120340.pdf. Accessed 11 July 2019.

49. Reichardt P, Tabone MD, Mora J, Morland B, Jones RL. Risk-benefit of dexrazoxane for preventing anthracycline-related cardiotoxicity: reevaluating the European labeling. Future Oncol. 2018;14(25):2663-76.

50. European Medicines Agency. Questions and answers on Cardioxane http:// www.ema.europa.eu/ema/index.jsp?curl=pages/medicines/human/referrals/ Cardioxane/human_referral_000421.jsp\&mid=WC0b01ac05805c516f Accessed 9 July 2019.
51. Lipshultz SE. Letter by Lipshultz regarding article, "anthracycline cardiotoxicity: worrisome enough to have you quaking?". Circ Res. 2018; 122(7):e62-3.

52. Pereira GC, Pereira SP, Pereira CV, Lumini JA, Magalhães J, Ascensão A, et al. Mitochondrionopathy phenotype in doxorubicin- treated Wistar rats depends on treatment protocol and is cardiac-specific. PLoS One. 2012;7(6): e38867.

53. Lipshultz SE, Scully RE, Lipsitz SR, Sallan SE, Silverman LB, Miller TL, et al. Assessment of dexrazoxane as a cardioprotectant in doxorubicintreated children with high-risk acute lymphoblastic leukaemia: longterm follow-up of a prospective, randomised, multicentre trial. Lancet Oncol. 2010;11(10):950-61.

54. Bernstein D. Response by Bernstein to letter regarding article, "anthracycline cardiotoxicity: worrisome enough to have you quaking?". Circ Res. 2018; 122(7):e64-5.

55. Hasinoff BB, Herman EH. Dexrazoxane: how it works in cardiac and tumor cells. Is it a prodrug or is it a drug? Cardiovasc Toxicol. 2007;7(2):140-4.

56. Hutchins KK, Siddeek H, Franco VI, Lipshultz SE. Prevention of cardiotoxicity among survivors of childhood cancer. Br J Clin Pharmacol. 2017;83(3):455-65.

57. Chang HM, Moudgil R, Scarabelli T, Okwuosa TM, Yeh ETH. Cardiovascular complications of cancer therapy: best practices in diagnosis, prevention, and management: part 1. J Am Coll Cardiol. 2017;70(20):2536-51.

58. Lipshultz SE, Herman EH. Anthracycline cardiotoxicity: the importance of horizontally integrating pre-clinical and clinical research. Cardiovasc Res. 2018;114(2):205-9.

59. Wexler LH, Andrich MP, Venzon D, Berg SL, Weaver-McClure L, Chen CC, et al. Randomized trial of the cardioprotective agent ICRF-187 in pediatric sarcoma patients treated with doxorubicin. J Clin Oncol. 1996;14(2):362-72.

60. Choi HS, Park ES, Kang HJ, Shin HY, Noh Cl, Yun YS, et al. Dexrazoxane for preventing anthracycline cardiotoxicity in children with solid tumors. J Korean Med Sci. 2010;25(9):1336-42.

61. Paiva MG, Petrilli AS, Moises VA, Macedo CR, Tanaka C, Campos O. Cardioprotective effect of dexrazoxane during treatment with doxorubicin: a study using low-dose dobutamine stress echocardiography. Pediatr Blood Cancer. 2005:45(7):902-8.

62. Asselin BL, Devidas M, Chen L, Franco VI, Pullen J, Borowitz MJ, et al. Cardioprotection and safety of dexrazoxane in patients treated for newly diagnosed t-cell acute lymphoblastic leukemia or advanced-stage lymphoblastic non-Hodgkin lymphoma: a report of the Children's oncology group randomized trial pediatric oncology group 9404. J Clin Oncol. 2016; 34(8):854-62.

63. Kang M, Kim Kl, Song YC, Shin WG, Oh JM. Cardioprotective effect of early dexrazoxane use in anthracycline treated pediatric patients. J Chemother. 2012:24(5):292-6.

64. van Dalen EC, Caron HN, Dickinson HO, Kremer LC. Cardioprotective interventions for cancer patients receiving anthracyclines. Cochrane Database Syst Rev. 2011;6:CD003917.

65. Ganatra S, Nohria A, Shah S, Groarke JD, Sharma A, Venesy D, et al. Upfront dexrazoxane for the reduction of anthracycline-induced cardiotoxicity in adults with preexisting cardiomyopathy and cancer: a consecutive case series. Cardio-Oncology. 2019;5(1):1

66. Smith LA, Cornelius VR, Plummer CJ, Levitt G, Verrill M, Canney P, et al. Cardiotoxicity of anthracycline agents for the treatment of cancer: systematic review and meta-analysis of randomised controlled trials. BMC Cancer. 2010;10:337.

67. Tebbi CK, London WB, Friedman D, Villaluna D, De Alarcon PA, Constine LS, et al. Dexrazoxane-associated risk for acute myeloid leukemia/ myelodysplastic syndrome and other secondary malignancies in pediatric Hodgkin's disease. J Clin Oncol. 2007;25(5):493-500.

68. Seif AE, Walker DM, Li Y, Huang YS, Kavcic M, Torp K, et al. Dexrazoxane exposure and risk of secondary acute myeloid leukemia in pediatric oncology patients. Pediatr Blood Cancer. 2015;62(4):704-9.

69. Vrooman LM, Neuberg DS, Stevenson KE, Asselin BL, Athale UH, Clavell L, et al. The low incidence of secondary acute myelogenous leukaemia in children and adolescents treated with dexrazoxane for acute lymphoblastic leukaemia: a report from the Dana-Farber Cancer Institute ALL consortium. Eur J Cancer. 2011:47(9):1373-9.

70. Chow EJ, Asselin BL, Schwartz CL, Doody DR, Leisenring WM, Aggarwal S, et al. Late mortality after dexrazoxane treatment: a report from the Children's oncology group. J Clin Oncol. 2015;33(24):2639-45. 
71. Kim H, Kang HJ, Park KD, Koh KN, Im HJ, Seo JJ, et al. Risk factor analysis for secondary malignancy in dexrazoxane-treated pediatric cancer patients. Cancer Res Treat. 2019;51(1):357-67.

72. Chow EJ, Doody DR, Armenian SH, Aggarwal S, Baker KS, Bhatia S, et al. Effect of dexrazoxane on heart function among long-term survivors of childhood leukemia and lymphoma: a report from the Children's oncology group (COG). Blood. 2016;128(22):696.

73. Desai VG, Lee T, Moland CL, Vijay V, Han T, Lewis SM, et al. Candidate early predictive plasma protein markers of doxorubicin-induced chronic cardiotoxicity in B6C3F1 mice. Toxicol Appl Pharmacol. 2019;363:164-73.

74. Lipshultz SE, Franco VI, Sallan SE, Adamson PC, Steiner RK, Swain SM, et al. Dexrazoxane for reducing anthracycline-related cardiotoxicity in children with cancer: an update of the evidence. Prog Pediatr Cardiol. 2014;36(1):39-49.

75. Renu K, V GA, P BT, Arunachalam S Molecular mechanism of doxorubicininduced cardiomyopathy — an update Eur J Pharmacol 2018;818:241-253.

76. Cappetta D, Rossi F, Piegari E, Quaini F, Berrino L, Urbanek K, et al. Doxorubicin targets multiple players: a new view of an old problem. Pharmacol Res. 2018;127:4-14.

77. Bernstein D, Fajardo G, Zhao M, Urashima T, Powers J, Berry G, et al. Differential cardioprotective/cardiotoxic effects mediated by beta-adrenergic receptor subtypes. Am J Physiol Heart Circ Physiol. 2005;289(6):H2441-9.

78. Thomas L, Bellmont S, Christen MO, La Roche B, Monassier L. Cardiovascular and survival effects of sympatho-inhibitors in adriamycin-induced cardiomyopathy in rats. Fundam Clin Pharmacol. 2004;18(6):649-55.

79. Fujita N, Hiroe M, Ohta Y, Horie T, Hosoda S. Chronic effects of metoprolol on myocardial beta-adrenergic receptors in doxorubicin-induced cardiac damage in rats. J Cardiovasc Pharmacol. 1991;17(4):656-61.

80. Fu LX, Bergh $\mathrm{CH}$, Hoebeke J, Liang QM, Sjogren KG, Waagstein F, et al. Effect of metoprolol on activity of beta-adrenoceptor coupled to guanine nucleotide binding regulatory proteins in adriamycin-induced cardiotoxicity. Basic Res Cardiol. 1991;86(2):117-26.

81. Chen YL, Chung SY, Chai HT, Chen CH, Liu CF, Chen YL, et al. Early administration of carvedilol protected against doxorubicin-induced cardiomyopathy. J Pharmacol Exp Ther. 2015;355(3):516-27.

82. Lipshultz SE, Anderson LM, Miller TL, Gerschenson M, Stevenson KE, Neuberg DS, et al. Impaired mitochondrial function is abrogated by dexrazoxane in doxorubicin-treated childhood acute lymphoblastic leukemia survivors. Cancer. 2016;122(6):946-53.

83. Kotsinas A, Gorgoulis V, Zacharatos P, Zioris H, Triposkiadis F, Donta I, et al. Antioxidant agent nimesulid and beta-blocker metoprolol do not exert protective effects against rat mitochondrial DNA alterations in adriamycininduced cardiotoxicity. Biochem Biophys Res Commun. 1999;254(3):651-6.

84. Bozcali E, Dedeoglu DB, Karpuz V, Suzer O, Karpuz H. Cardioprotective effects of zofenopril, enalapril and valsartan against ischaemia/reperfusion injury as well as doxorubicin cardiotoxicity. Acta Cardiol. 2012;67(1):87-96.

85. Hiona A, Lee AS, Nagendran J, Xie X, Connolly AJ, Robbins RC, et al. Pretreatment with angiotensin-converting enzyme inhibitor improves doxorubicin-induced cardiomyopathy via preservation of mitochondrial function. J Thorac Cardiovasc Surg. 2011;142(2):396-403 e3.

86. Avila MS, Ayub-Ferreira SM, de Barros Wanderley MR, Jr., das Dores Cruz F, Goncalves Brandao SM, Rigaud VOC, et al. Carvedilol for prevention of chemotherapy-related cardiotoxicity: the CECCY trial. J Am Coll Cardio 2018;71(20):2281-2290.

87. Kalay N, Basar E, Ozdogru I, Er O, Cetinkaya Y, Dogan A, et al. Protective effects of carvedilol against anthracycline-induced cardiomyopathy. J Am Coll Cardiol. 2006;48(11):2258-62.

88. Tashakori Beheshti A, Mostafavi Toroghi H, Hosseini G, Zarifian A, Homaei Shandiz F, Fazlinezhad A. Carvedilol administration can prevent doxorubicin-induced cardiotoxicity: a double-blind randomized trial. Cardiology. 2016;134(1):47-53.

89. Elitok A, Oz F, Cizgici AY, Kilic L, Ciftci R, Sen F, et al. Effect of carvedilol on silent anthracycline-induced cardiotoxicity assessed by strain imaging: a prospective randomized controlled study with six-month follow-up. Cardiol J. 2014;21(5):509-15.

90. Jhorawat R, Kumari S, Varma SC, Rohit MK, Narula N, Suri V, et al. Preventive role of carvedilol in Adriamycin-induced cardiomyopathy. Indian J Med Res. 2016;144(5):725-9.

91. Kheiri B, Abdalla A, Osman M, Haykal T, Chahine A, Ahmed S, et al. Metaanalysis of carvedilol for the prevention of anthracycline-induced cardiotoxicity. Am J Cardiol. 2018;122(11):1959-64.
92. Kaya MG, Ozkan M, Gunebakmaz O, Akkaya H, Kaya EG, Akpek M, et al. Protective effects of nebivolol against anthracycline-induced cardiomyopathy: a randomized control study. Int J Cardiol. 2013;167(5):2306-10.

93. Cardinale D, Ciceri F, Latini R, Franzosi MG, Sandri MT, Civelli M, et al. Anthracycline-induced cardiotoxicity: a multicenter randomised trial comparing two strategies for guiding prevention with enalapril: the international CardioOncology society-one trial. Eur J Cancer. 2018;94:126-37.

94. Janbabai G, Nabati M, Faghihinia M, Azizi S, Borhani S, Yazdani J. Effect of enalapril on preventing anthracycline-induced cardiomyopathy. Cardiovasc Toxicol. 2017;17(2):130-9.

95. Nakamae H, Tsumura K, Terada Y, Nakane T, Nakamae M, Ohta K, et al. Notable effects of angiotensin II receptor blocker, valsartan, on acute cardiotoxic changes after standard chemotherapy with cyclophosphamide, doxorubicin, vincristine, and prednisolone. Cancer. 2005;104(11):2492-8.

96. Nabati M, Janbabai G, Baghyari S, Esmaili K, Yazdani J. Cardioprotective effects of carvedilol in inhibiting doxorubicin-induced cardiotoxicity. J Cardiovasc Pharmacol. 2017:69(5):279-85.

97. Georgakopoulos P, Roussou P, Matsakas E, Karavidas A, Anagnostopoulos N, Marinakis T, et al. Cardioprotective effect of metoprolol and enalapril in doxorubicin-treated lymphoma patients: a prospective, parallel-group, randomized, controlled study with 36-month follow-up. Am J Hematol. 2010;85(11):894-6.

98. Wittayanukorn S, Qian J, Westrick SC, Billor N, Johnson B, Hansen RA. Prevention of trastuzumab and anthracycline-induced cardiotoxicity using angiotensin-converting enzyme inhibitors or beta-blockers in older adults with breast cancer. Am J Clin Oncol. 2018:41(9):909-18.

99. Kalam K, Marwick TH. Role of cardioprotective therapy for prevention of cardiotoxicity with chemotherapy: a systematic review and meta-analysis. Eur J Cancer. 2013;49(13):2900-9.

100. Seicean S, Seicean A, Alan N, Plana JC, Budd GT, Marwick TH. Cardioprotective effect of beta-adrenoceptor blockade in patients with breast cancer undergoing chemotherapy: follow-up study of heart failure. Circ Heart Fail. 2013;6(3):420-6.

101. Liu G, Liu Y, Wang R, Hou T, Chen C, Zheng S, et al. Spironolactone attenuates doxorubicin-induced cardiotoxicity in rats. Cardiovasc Ther. 2016; 34(4):216-24.

102. Yavas G, Celik E, Yavas C, Elsurer C, Afsar RE. Spironolactone ameliorates the cardiovascular toxicity induced by concomitant trastuzumab and thoracic radiotherapy. Rep Pract Oncol Radiother. 2017;22(4):295-302.

103. Lipshultz SE, Cohen H, Colan SD, Herman EH. The relevance of information generated by in vitro experimental models to clinical doxorubicin cardiotoxicity. Leuk Lymphoma. 2006;47(8):1454-8.

104. Akpek M, Ozdogru I, Sahin O, Inanc M, Dogan A, Yazici C, et al. Protective effects of spironolactone against anthracycline-induced cardiomyopathy. Eur J Heart Fail. 2015;17(1):81-9.

105. Gupta V, Kumar Singh S, Agrawal V, Bali ST. Role of ACE inhibitors in anthracycline-induced cardiotoxicity: a randomized, double-blind, placebocontrolled trial. Pediatr Blood Cancer. 2018 Nov;65(11):e27308.

106. El-Shitany NA, Tolba OA, El-Shanshory MR, El-Hawary EE. Protective effect of carvedilol on Adriamycin-induced left ventricular dysfunction in children with acute lymphoblastic leukemia. J Card Fail. 2012;18(8):607-13.

107. Henriksen PA. Anthracycline cardiotoxicity: an update on mechanisms, monitoring and prevention. Heart. 2018 Jun;104(12):971-7.

108. Lipshultz SE, Adams MJ. Cardiotoxicity after childhood cancer: beginning with the end in mind. J Clin Oncol. 2010;28(8):1276-81.

109. Lipshultz SE, Colan SD. Cardiovascular trials in long-term survivors of childhood cancer. J Clin Oncol. 2004;22(5):769-73.

110. Minotti G, Menna P, Salvatorelli E, Cairo G, Gianni L. Anthracyclines: molecular advances and pharmacologic developments in antitumor activity and cardiotoxicity. Pharmacol Rev. 2004;56(2):185-229.

111. Gianni L, Herman EH, Lipshultz SE, Minotti G, Sarvazyan N, Sawyer DB. Anthracycline cardiotoxicity: from bench to bedside. J Clin Oncol. 2008; 26(22):3777-84.

112. Horenstein MS, Vander Heide RS, L'Ecuyer TJ. Molecular basis of anthracycline-induced cardiotoxicity and its prevention. Mol Genet Metab. 2000;71(1-2):436-44.

113. Lebrecht D, Setzer B, Ketelsen UP, Haberstroh J, Walker UA. Time-dependent and tissue-specific accumulation of mtDNA and respiratory chain defects in chronic doxorubicin cardiomyopathy. Circulation. 2003;108(19):2423-9.

114. Seicean S, Seicean A, Plana JC, Budd GT, Marwick TH. Effect of statin therapy on the risk for incident heart failure in patients with breast cancer receiving 
anthracycline chemotherapy: an observational clinical cohort study. J Am Coll Cardiol. 2012:60(23):2384-90.

115. Chotenimitkhun R, D'Agostino R Jr, Lawrence JA, Hamilton CA, Jordan JH,

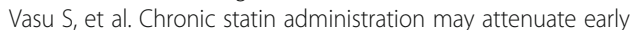
anthracycline-associated declines in left ventricular ejection function. Can J Cardiol. 2015:31(3):302-7.

116. Acar Z, Kale A, Turgut M, Demircan S, Durna K, Demir S, et al. Efficiency of atorvastatin in the protection of anthracycline-induced cardiomyopathy. J Am Coll Cardiol. 2011;58(9):988-9.

117. Lloyd-Jones DM, Goff D, Stone NJ. Statins, risk assessment, and the new American prevention guidelines. Lancet. 2014;383(9917):600-2.

118. Expert panel on integrated guidelines for cardiovascular health and risk reduction in children and adolescents: summary report. Pediatrics. 2011; 128(Suppl 5):S213-56. PMID 22084329.

119. Lipshultz SE, Schaechter J, Carrillo A, Sanchez J, Qureshi MY, Messiah SE, et al. Can the consequences of universal cholesterol screening during childhood prevent cardiovascular disease and thus reduce long-term health care costs? Pediatr Endocrinol Rev. 2012;9(4):698-705.

120. Ogden CL, Carroll MD, Kit BK, Flegal KM. Prevalence of childhood and adult obesity in the United States, 2011-2012. JAMA. 2014;311(8):806-14.

121. Meacham LR, Gurney JG, Mertens AC, Ness KK, Sklar CA, Robison LL, et al. Body mass index in long-term adult survivors of childhood cancer: a report of the childhood Cancer survivor study. Cancer. 2005;103(8):1730-9.

122. van Santen HM, Geskus RB, Raemaekers S, van Trotsenburg AS, Vulsma T, van der Pal HJ, et al. Changes in body mass index in long-term childhood cancer survivors. Cancer. 2015;121(23):4197-204.

123. Lipshultz SE, Landy DC, Lopez-Mitnik G, Lipsitz SR, Hinkle AS, Constine LS, et al. Cardiovascular status of childhood cancer survivors exposed and unexposed to cardiotoxic therapy. J Clin Oncol. 2012;30(10):1050-7.

124. Miller TL, Lipsitz SR, Lopez-Mitnik G, Hinkle AS, Constine LS, Adams MJ, et al. Characteristics and determinants of adiposity in pediatric cancer survivors. Cancer Epidemiol Biomark Prev. 2010;19(8):2013-22.

125. Felicetti F, D'Ascenzo F, Moretti C, Corrias A, Omede P, Marra WG, et al. Prevalence of cardiovascular risk factors in long-term survivors of childhood cancer: 16 years follow up from a prospective registry. Eur J Prev Cardiol. 2015;22(6):762-70

126. Talvensaari KK, Lanning M, Tapanainen P, Knip M. Long-term survivors of childhood cancer have an increased risk of manifesting the metabolic syndrome. J Clin Endocrinol Metab. 1996;81(8):3051-5.

127. Gurney JG, Ness KK, Sibley SD, O'Leary M, Dengel DR, Lee JM, et al. Metabolic syndrome and growth hormone deficiency in adult survivors of childhood acute lymphoblastic leukemia. Cancer. 2006;107(6):1303-12.

128. Pluimakers VG, van Waas M, Neggers S, van den Heuvel-Eibrink MM. Metabolic syndrome as cardiovascular risk factor in childhood cancer survivors. Crit Rev Oncol Hematol. 2019;133:129-41.

129. Berdan CA, Tangney CC, Scala C, Stolley M. Childhood cancer survivors and adherence to the American Cancer Society guidelines on nutrition and physical activity. J Cancer Surviv. 2014;8(4):671-9.

130. Ness KK, Leisenring WM, Huang S, Hudson MM, Gurney JG, Whelan K, et al. Predictors of inactive lifestyle among adult survivors of childhood cancer: a report from the childhood Cancer survivor study. Cancer. 2009;115(9):1984-94.

131. Miller AM, Lopez-Mitnik G, Somarriba G, Lipsitz SR, Hinkle AS, Constine LS, et al. Exercise capacity in long-term survivors of pediatric cancer: an analysis from the cardiac risk factors in childhood Cancer survivors study. Pediatr Blood Cancer. 2013;60(4):663-8

132. Adams MJ, Lipsitz SR, Colan SD, Tarbell NJ, Treves ST, Diller L, et al. Cardiovascular status in long-term survivors of Hodgkin's disease treated with chest radiotherapy. J Clin Oncol. 2004;22(15):3139-48.

133. Christiansen JR, Kanellopoulos A, Lund MB, Massey R, Dalen H, Kiserud CE, et al. Impaired exercise capacity and left ventricular function in long-term adult survivors of childhood acute lymphoblastic leukemia. Pediatr Blood Cancer. 2015;62(8):1437-43.

134. Kenzik KM, Demark-Wahnefried W, Ganz PA, Colditz G, Rock CL, Rogers LQ. Changes in body mass index and physical activity predict changes in vitality during a weight loss trial in breast cancer survivors. Ann Behav Med. 2018; 52(12):999-1009.

135. Cifra B, Chen CK, Fan CS, Slorach C, Manlhiot C, McCrindle BW, et al. Dynamic myocardial response to exercise in childhood cancer survivors treated with anthracyclines. J Am Soc Echocardiogr. 2018;31(8):933-42.

136. Schmitz KH, Courneya KS, Matthews C, Demark-Wahnefried W, Galvao DA, Pinto BM, et al. American College of Sports Medicine roundtable on exercise guidelines for cancer survivors. Med Sci Sports Exerc. 2010;42(7): 1409-26.

137. Scharhag-Rosenberger F, Kuehl R, Klassen O, Schommer K, Schmidt ME, Ulrich CM, et al. Exercise training intensity prescription in breast cancer survivors: validity of current practice and specific recommendations. J Cancer Surviv. 2015;9(4):612-9.

138. Buffart LM, Sweegers MG, May AM, Chinapaw MJ, van Vulpen JK, Newton $\mathrm{RU}$, et al. Targeting exercise interventions to patients with cancer in need: an individual patient data meta-analysis. J Natl Cancer Inst. 2018;110(11): 1190-200.

139. Steiner R. Increasing exercise in long-term survivors of pediatric cancer and their siblings: should treatment be a family affair? Pediatr Blood Cancer. 2013;60(4):529-30.

140. Li HC, Chung OK, Ho KY, Chiu SY, Lopez V. Effectiveness of an integrated adventure-based training and health education program in promoting regular physical activity among childhood cancer survivors. Psychooncology. 2013;22(11):2601-10.

141. Gilchrist SC, Barac A, Ades PA, Alfano CM, Franklin BA, Jones LW, et al. Cardio-oncology rehabilitation to manage cardiovascular outcomes in cancer patients and survivors: a scientific statement from the American Heart Association. Circulation. 2019;139(21):e997-e1012.

142. Armenian SH, Hudson MM, Mulder RL, Chen MH, Constine LS, Dwyer M, et al. Recommendations for cardiomyopathy surveillance for survivors of childhood cancer: a report from the international late effects of childhood Cancer guideline harmonization group. Lancet Oncol. 2015;16(3):e123-36.

143. He L, Xiao J, Fu H, Du G, Xiao X, Zhang C, et al. Effect of oxidative stress on ventricular arrhythmia in rabbits with Adriamycin-induced cardiomyopathy. J Huazhong Univ Sci Technolog Med Sci. 2012;32(3):334-9.

144. Noori A, Lindenfeld J, Wolfel E, Ferguson D, Bristow MR, Lowes BD. Beta-blockade in adriamycin-induced cardiomyopathy. J Card Fail. 2000; 6(2):115-9.

145. Cardinale D, Colombo A, Sandri MT, Lamantia G, Colombo N, Civelli M, et al. Prevention of high-dose chemotherapy-induced cardiotoxicity in high-risk patients by angiotensin-converting enzyme inhibition. Circulation. 2006; 114(23):2474-81.

146. Cardinale D, Colombo A, Lamantia G, Colombo N, Civelli M, De Giacomi G, et al. Anthracycline-induced cardiomyopathy: clinical relevance and response to pharmacologic therapy. J Am Coll Cardiol. 2010;55(3):213-20.

147. Kober L, Thune JJ, Nielsen JC, Haarbo J, Videbaek L, Korup E, et al. Defibrillator implantation in patients with nonischemic systolic heart failure. N Engl J Med. 2016;375(13):1221-30.

148. Rickard J, Kumbhani DJ, Baranowski B, Martin DO, Tang WH, Wilkoff BL. Usefulness of cardiac resynchronization therapy in patients with Adriamycin-induced cardiomyopathy. Am J Cardiol. 2010;105(4):522-6.

149. Shaddy RE, Olsen SL, Bristow MR, Taylor DO, Bullock EA, Tani LY, et al. Efficacy and safety of metoprolol in the treatment of doxorubicin-induced cardiomyopathy in pediatric patients. Am Heart J. 1995;129(1):197-9.

150. Harrington JK, Richmond ME, Fein AW, Kobsa S, Satwani P, Shah A. Twodimensional speckle tracking echocardiography-derived strain measurements in survivors of childhood cancer on angiotensin converting enzyme inhibition or receptor blockade. Pediatr Cardiol. 2018;39(7):1404-12.

151. Lipshultz SE, Lipsitz SR, Sallan SE, Simbre VC 2nd, Shaikh SL, Mone SM, et al. Long-term enalapril therapy for left ventricular dysfunction in doxorubicintreated survivors of childhood cancer. J Clin Oncol. 2002;20(23):4517-22.

152. Silber JH, Cnaan A, Clark BJ, Paridon SM, Chin AJ, Rychik J, et al. Enalapril to prevent cardiac function decline in long-term survivors of pediatric cancer exposed to anthracyclines. J Clin Oncol. 2004;22(5):820-8.

153. Cheuk DK, Sieswerda E, van Dalen EC, Postma A, Kremer LC. Medical interventions for treating anthracycline-induced symptomatic and asymptomatic cardiotoxicity during and after treatment for childhood cancer. Cochrane Database Syst Rev. 2016;8:CD008011.

154. Armenian SH, Hudson MM, Chen MH, Colan SD, Lindenfeld L, Mills G, et al. Rationale and design of the Children's oncology group (COG) study ALTE1621: a randomized, placebo-controlled trial to determine if low-dose carvedilol can prevent anthracycline-related left ventricular remodeling in childhood cancer survivors at high risk for developing heart failure. BMC Cardiovasc Disord. 2016;16(1):187.

155. Moslehi JJ. Cardiovascular toxic effects of targeted cancer therapies. N Engl J Med. 2016;375(15):1457-67.

156. Ganatra S, Neilan TG. Immune checkpoint inhibitor-associated myocarditis. Oncologist. 2018;23(8):879-86. 
157. Sorensen GV, Ganz PA, Cole SW, Pedersen LA, Sorensen HT, Cronin-Fenton DP, et al. Use of beta-blockers, angiotensin-converting enzyme inhibitors, angiotensin II receptor blockers, and risk of breast cancer recurrence: a Danish nationwide prospective cohort study. J Clin Oncol. 2013:31(18):2265-72.

158. Stati T, Musumeci M, Maccari S, Massimi A, Corritore E, Strimpakos G, et al. Beta-blockers promote angiogenesis in the mouse aortic ring assay. J Cardiovasc Pharmacol. 2014;64(1):21-7.

159. Jansen L, Weberpals J, Kuiper JG, Vissers PAJ, Wolkewitz M, Hoffmeister M, et al. Pre- and post-diagnostic beta-blocker use and prognosis after colorectal cancer: results from a population-based study. Int J Cancer. 2017;141(1):62-71.

160. Jansen L, Below J, Chang-Claude J, Brenner H, Hoffmeister M. Beta blocker use and colorectal cancer risk: population-based case-control study. Cancer. 2012;118(16):3911-9.

161. Pfeffer MA, Swedberg K, Granger CB, Held P, McMurray JJ, Michelson EL, et al. Effects of candesartan on mortality and morbidity in patients with chronic heart failure: the CHARM-overall programme. Lancet. 2003; 362(9386):759-66.

162. Sipahi I, Debanne SM, Rowland DY, Simon DI, Fang JC. Angiotensin-receptor blockade and risk of cancer: meta-analysis of randomised controlled trials. Lancet Oncol. 2010;11(7):627-36.

163. Zhao YT, Li PY, Zhang JQ, Wang L, Yi Z. Angiotensin II receptor blockers and cancer risk: a meta-analysis of randomized controlled trials. Medicine (Baltimore). 2016;95(18):e3600.

164. USA today. https://www.usatoday.com/story/money/nation-now/201 8/11/13/fda-losartan-recall-cancer-risk-tied-blood-pressure-drug/198585 8002/. Accessed 8 Apr 2019.

165. Nardone B, Majewski S, Kim AS, Kiguradze T, Martinez-Escala EM, Friedland $R$, et al. Melanoma and non-melanoma skin cancer associated with angiotensin-converting-enzyme inhibitors, angiotensin-receptor blockers and thiazides: a matched cohort study. Drug Saf. 2017;40(3):249-55.

166. Bangalore S, Kumar S, Kjeldsen SE, Makani H, Grossman E, Wetterslev J, et al. Antihypertensive drugs and risk of cancer: network meta-analyses and trial sequential analyses of 324,168 participants from randomised trials. Lancet Oncol. 2011;12(1):65-82.

167. Sipahi I, Chou J, Mishra P, Debanne SM, Simon DI, Fang JC. Meta-analysis of randomized controlled trials on effect of angiotensin-converting enzyme inhibitors on cancer risk. Am J Cardiol. 2011;108(2):294-301.

168. Hicks BM, Filion KB, Yin H, Sakr L, Udell JA, Azoulay L. Angiotensin converting enzyme inhibitors and risk of lung cancer: population based cohort study. BMJ. 2018;363:k4209.

169. Pitt B, Zannad F, Remme WJ, Cody R, Castaigne A, Perez A, et al. The effect of spironolactone on morbidity and mortality in patients with severe heart failure. Randomized Aldactone evaluation study investigators. N Engl J Med. 1999:341(10):709-17.

170. Mackenzie IS, Morant SV, Wei L, Thompson AM, MacDonald TM. Spironolactone use and risk of incident cancers: a retrospective, matched cohort study. Br J Clin Pharmacol. 2017;83(3):653-63.

171. Mackenzie IS, Macdonald TM, Thompson A, Morant S, Wei L. Spironolactone and risk of incident breast cancer in women older than 55 years: retrospective, matched cohort study. Bmj. 2012;345:e4447.

172. Lipshultz SE SR, Stevenson KE, Franco VI, Neuberg DS, Colan SD, et al. Hearts too small for body size after doxorubicin for childhood ALL: Grinch syndrome. J Clin Oncol 2014;(32:10021 (abstract)).

173. Shakir DK, Rasul Kl. Chemotherapy induced cardiomyopathy: pathogenesis, monitoring and management. J Clin Med Res. 2009;1(1):8-12.

174. Smith GL, Smith BD, Buchholz TA, Giordano SH, Garden AS, Woodward WA, et al. Cerebrovascular disease risk in older head and neck cancer patients after radiotherapy. J Clin Oncol. 2008;26(31):5119-25.

175. Martin RA, Jones KL, Mendoza A, Barr M Jr, Benirschke K. Effect of ACE inhibition on the fetal kidney: decreased renal blood flow. Teratology. 1992; 46(4):317-21.

176. Lipshultz SE, Barach PR, Wilkinson JD. Does lowering heart rate improve outcomes in children with dilated cardiomyopathy and chronic heart failure? J Am Coll Cardiol. 2017;70(10):1273-5.

177. Ganatra S, Hayek SS. Cardio-Oncology for GenNext: A Missing Piece of the Training Puzzle. J Am Coll Cardiol. 2018;71(25):2977-81.

\section{Publisher's Note}

Springer Nature remains neutral with regard to jurisdictional claims in published maps and institutional affiliations.

\section{Ready to submit your research? Choose BMC and benefit from:}

- fast, convenient online submission

- thorough peer review by experienced researchers in your field

- rapid publication on acceptance

- support for research data, including large and complex data types

- gold Open Access which fosters wider collaboration and increased citations

- maximum visibility for your research: over $100 \mathrm{M}$ website views per year

At $\mathrm{BMC}$, research is always in progress.

Learn more biomedcentral.com/submissions 